\title{
Nationwide urban ground deformation monitoring in Japan using Sentinel-1 LiCSAR products and LiCSBAS
}

\author{
Yu Morishita(1)
}

\begin{abstract}
Ground subsidence in urban areas is a significant problem because it increases flood risk, damages buildings and infrastructure, and results in economic loss. Continual monitoring of ground deformation is important for early detection, mechanism understanding, countermeasure implementation, and deformation prediction. The Sentinel-1 satellite constellation has globally and freely provided frequent and abundant SAR data and enabled nationwide deformation monitoring through InSAR time series analysis. LiCSAR, an automatic Sentinel-1 interferometric processing system, has produced abundant interferograms with global coverage, and the products are freely accessible and downloadable through a web portal. LiCSBAS, an open source InSAR time series analysis package integrated with LiCSAR, enables users to obtain the deformation time series easily and quickly. In this study, spatially and temporally detailed deformation time series and velocities from the LiCSAR products using LiCSBAS for 73 major urban areas in Japan during 2014-2020 were derived. All LiCSBAS processing was automatically performed using predefined parameters. Many deformation signals with various temporal and spatial features, such as linear subsidence in Hirosaki, Kujyukuri, Niigata, and Kanazawa, episodic subsidence in Sanjo, annual vertical fluctuation in Hirosaki, Yamagata, Yonezawa, Ojiya, and Nogi, and linear uplift in Chofu were detected. Unknown small nonlinear uplift signals were found in Nara and Osaka in 2018. Complex postseismic deformations from the 2016 Kumamoto earthquake were also revealed. All the deformation data obtained in this study are available on an open repository and are expected to be used for further research, investigation, or interpretation. This nationwide monitoring approach using the LiCSAR products and LiCSBAS is easy to implement and applicable to other areas worldwide.
\end{abstract}

Keywords: Automatic processing, Ground deformation, InSAR, Nationwide, Sentinel-1, Subsidence, Time series analysis

\section{Introduction}

Ground subsidence poses significant threats, especially in highly populated areas, because it increases flood risk, damages buildings and infrastructure, and results in economic loss. Many cities have experienced anthropogenic subsidence due to the fluid extraction of groundwater, oil, or natural gas, combined with rapid urbanization, or industrialization. For example, in Japan, significant subsidence has been observed in Tokyo ( $>4 \mathrm{~m}$ in total)

Correspondence: morishita-y96pt@mlit.go.jp

Geography and Crustal Dynamics Research Center, Geospatial Information Authority of Japan, 1 Kitasato, Tsukuba, Ibaraki 305-0811, Japan since the beginning of the twentieth century and spread to alluvial plains across the country in the 1950s (Yamamoto 1995; Tokyo Metropolitan Government 2019; Ministry of the Environment 2020). To prevent rapid anthropogenic subsidence, laws to control groundwater usage were enacted in 1956. As a result of new policies, ground subsidence has remarkably decreased since the 1970s.

Continual ground deformation monitoring is important for early detection of subsidence, understanding the deformation mechanisms, implementing countermeasures, and predicting future deformation. Leveling 
surveys and the Global Navigation Satellite System (GNSS) have traditionally been used to monitor ground subsidence with high accuracy $(\sim \mathrm{mm})$. However, these techniques obtain only pointwise deformation data and are costly and time consuming. Synthetic Aperture Radar (SAR) Interferometry (InSAR) has also been used for monitoring since the 1990s, and the InSAR time series analysis that can achieve higher accuracy $(\sim \mathrm{mm} /$ year) than that of conventional InSAR $(\sim \mathrm{cm})$ has substantially enhanced the capability of slow subsidence monitoring since the 2000s (e.g., Bell et al. 2008; Chaussard et al. 2013). In Japan, many case studies using conventional InSAR and the time series analysis with Japanese Earth Resources Satellite-1 (JERS-1), Advanced Land Observing Satellite (ALOS), and ALOS-2 data have detected various subsidence signals (e.g., Nakagawa et al. 2000; Morishita et al. 2010; Nonaka et al. 2020). However, the temporal sampling frequency was generally low, and therefore, it was difficult to determine the (nonlinear) temporal deformation signal features.

The C-band Sentinel-1 constellation launched by the European Space Agency (ESA) in 2014 and 2016 has been able to provide frequent and abundant data globally and freely (Potin et al. 2019). Several public nationwide deformation monitoring services using Sentinel-1 data are in operation or planned in Denmark, Germany, Italy, the Netherlands, and Norway (Crosetto et al. 2020), as well as commercial services for Denmark, Japan, France, and California in the USA (Bischoff et al. 2020).

The Looking Inside the Continents from Space (LiCS) project by the Centre for the Observation and Modelling of Earthquakes, Volcanoes, and Tectonics (COMET) also uses Sentinel-1 data for large-scale deformation monitoring. The Looking into Continents from Space with Synthetic Aperture Radar (LiCSAR) system, an automatic Sentinel-1 interferometric processing system, makes the products freely accessible and downloadable through a web portal (COMET 2020; Lazecký et al. 2020). LiCSBAS, an open source InSAR time series analysis package integrated with LiCSAR, can almost automatically conduct time series analysis using freely available LiCSAR products (Morishita et al. 2020). Weiss et al. (2020) derived the velocity and strain rate fields over the approximately $800,000 \mathrm{~km}^{2}$ Anatolian region from roughly 300,000 LiCSAR products (i.e., unwrapped interferograms) using LiCSBAS and revealed large-scale tectonic deformation as well as localized strain accumulation and subsidence with high spatial resolution. The LiCSAR products and LiCSBAS enable users to obtain the deformation time series quickly and easily, using only free and open resources without a highperformance computing facility that is required for general InSAR processing.
In this study, the deformation time series and velocities in major urban areas in Japan were derived from the LiCSAR products using LiCSBAS. The majority of the processing was performed automatically with predefined parameters. Many subsidence signals, as well as other types of deformation with various spatial and temporal features, were detected with high accuracy. All processed data (i.e., deformation time series, velocities, and noise indices) are available on an open repository (see "Availability of data and material"), can be easily displayed by the time series viewer in LiCSBAS or geographic information system (GIS) software, and are expected to be used for further research, investigation, or interpretation of the deformation signals. This study also demonstrates the feasibility of nationwide deformation monitoring using the LiCSAR products and LiCSBAS and their applicability to other areas worldwide.

\section{Data and methods}

\subsection{Data}

Sentinel-1 unwrapped and geocoded interferograms and corresponding coherence data $\left(0.001^{\circ}\right.$ resolution) were processed by LiCSAR and published on the COMETLiCSAR web portal (COMET 2020). There are 34 LiCSAR frames (18 and 16 in ascending and descending orbits, respectively) covering Japan (Fig. 1, Table 1) over an observation period from November 2014 to April 2020. The naming convention of the LiCSAR frame ID is OOOP_AAAAA_BBBBBB, where OOO denotes the number of the relative orbit, $\mathrm{P}$ denotes the orbital direction (i.e., descending (D) or ascending (A)), AAAAA is a colatitude identifier, and $\mathrm{BBBBBB}$ identifies the number of included bursts (Lazecký et al. 2020). While the general acquisition interval was primarily 24 days before the end of 2016, it shortened to 12 days after 2017 because of the start of the Sentinel-1B operation. Each frame has 240-430 (350 on average) interferograms derived from 70-140 (110 on average) acquisitions (i.e., three or four interferometric pairs for each acquisition with the preceding acquisitions; Lazecký et al. 2020). In total, $\sim 12$, 000 interferograms and $\sim 4,000$ acquisitions were used. The spatial baselines are almost always within $300 \mathrm{~m}$.

Notably, the acquisition start dates are not consistent for all frames because of the non-uniform observation strategy of Sentinel-1. For example, the earliest acquisition in 127A_06256_070603 and 170A_04675_131008 is April 30, 2016 and January 4, 2016, respectively, which means the deformation from 2014-2015 cannot be measured in these frames. There are also long acquisition gaps halfway through the observation period in some tracks and frames. For example, almost no data were acquired between June 2018 and June 2019 in 054A, December 2016 and November 2017 in 010A, July 2018 


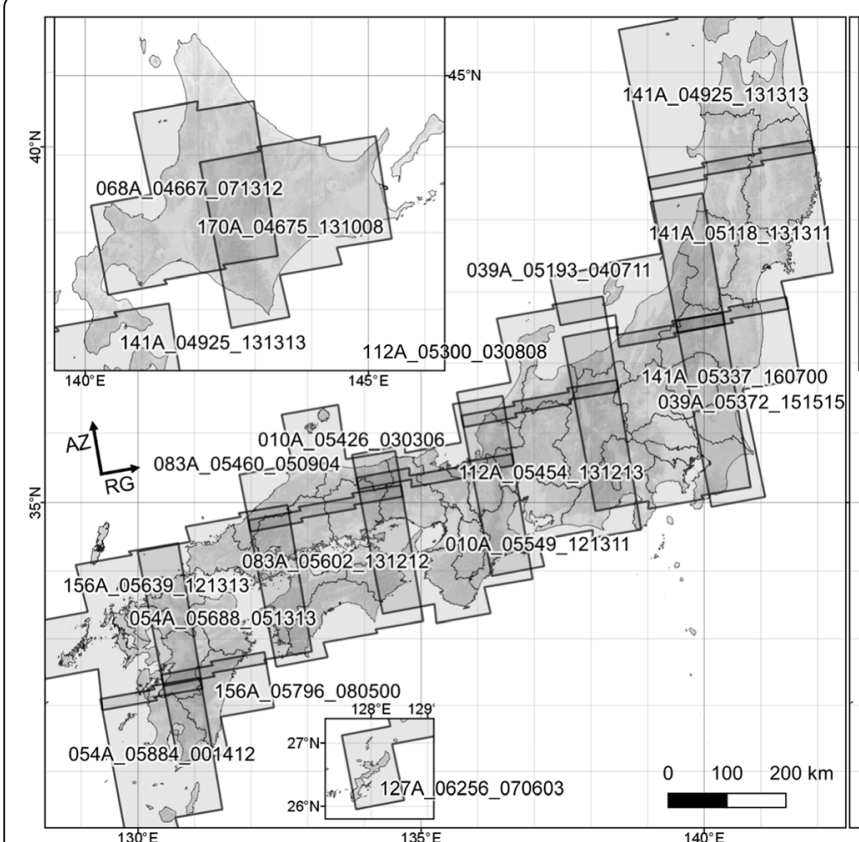

(a)

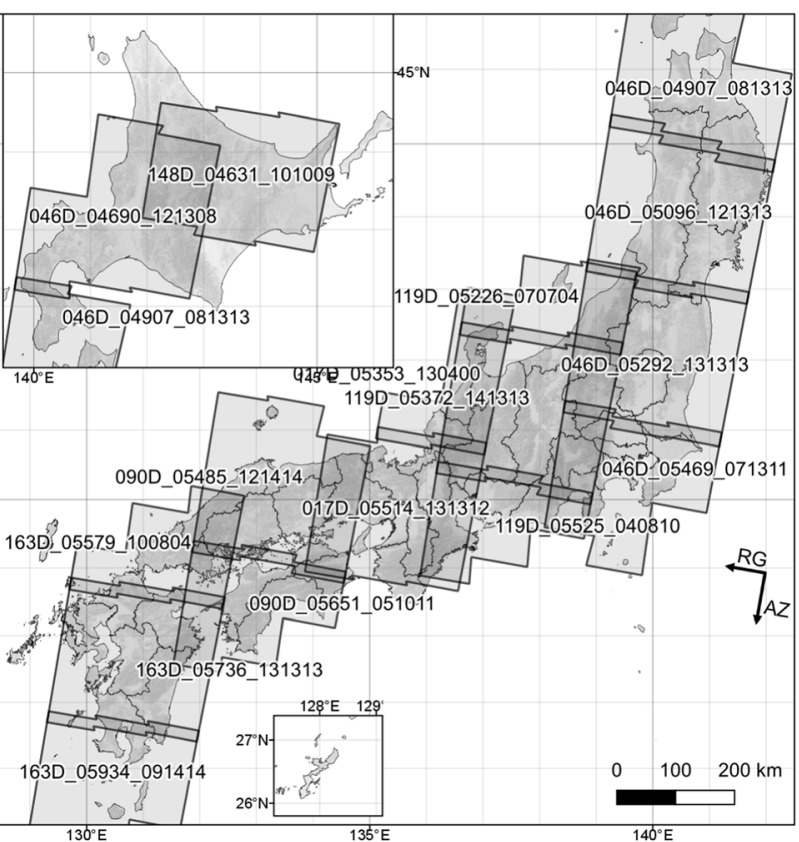

(b)

Fig. 1 Footprints of Sentinel-1 LiCSAR frames over Japan. a Ascending. b Descending

and July 2019 in 156A, and December 2015 and October 2016 in 163D_05579_100804.

\subsection{Target areas}

Most $(\sim 70 \%)$ national lands in Japan are covered with forests (Figs. 2 and S1). Dense vegetation prevents Cband SAR data from obtaining sufficient coherence in an interferogram, even with short temporal baselines (Rosen et al. 1996; Morishita et al. 2020), and tends to yield unwanted unwrapping errors. To avoid the impact of unwrapping errors and save the processing time and storage, this study focuses on urban areas. The 73 target urban areas are defined based on the densely inhabited district (DID; Ministry of Land, Infrastructure, Transport and Tourism 2015) metric, and compliance with at least one of the following conditions (Table 2, Figs. 2 and S1):

(1) Having a population of $\geq 100,000$.

(2) Having a population of $<100,000$ but near (1).

(3) In the 47 prefectural capitals.

(4) Leveling surveys have been continuously conducted (Ministry of the Environment 2020).

(5) Clear deformation has been detected by past studies (e.g., Morishita et al. 2020).

The area ID with triple digits consists of a double digits prefectural ID (01-47, e.g., 01 Hokkaido) and a single digit sub-number. As clear deformation has been detected outside of the DID in Hirosaki (ID: 022), Kanto (ID: 131), and Kumamoto (ID: 431) by past studies (e.g., Morishita et al. 2010; Nonaka et al. 2020; Hashimoto 2020), their target areas were expanded to measure complete deformation signals. All the defined areas except Naha (ID: 471) had at least one ascending and descending data set each, and some had two data sets due to overlapping areas between adjacent tracks (Fig. 1). All 191 available data sets for the defined clipped areas were processed (Table 2).

\subsection{Methods}

LiCSBAS (v1.3) for the InSAR time series analysis (Morishita et al. 2020) was used in this work. The LiCSBAS processing flow involves five steps for data preparation (step $0-1$ to $0-5$ ) and six steps for time series analysis (step 1-1 to 1-6). Each step is briefly discussed below. For further detailed information, please refer to Morishita et al. (2020).

Step 0-1: Download LiCSAR products

Step 0-2: Convert file format

Step 0-3: Tropospheric noise correction (optional)

Step 0-4: Mask low coherence areas in the unwrapped interferograms (optional)

Step 0-5: Clip a specified rectangular area of interest (optional)

Step 1-1: Quality check and identify bad interferograms

Step 1-2: Loop closure check and identify bad interferograms

Step 1-3: Small baseline inversion

Step 1-4: Calculate standard deviations of the velocity

Step 1-5: Mask time series

Step 1-6: Filter (and deramp) time series 
Table 1 LiCSAR frames, observation periods, and number of data used in this study

\begin{tabular}{|c|c|c|c|c|c|}
\hline \multirow[t]{2}{*}{ Frame ID } & \multicolumn{2}{|c|}{ Date (yyyymmdd) } & \multirow{2}{*}{$\begin{array}{l}\text { Period } \\
\text { (year) }\end{array}$} & \multirow{2}{*}{$\begin{array}{l}\# \\
\text { Image }\end{array}$} & \multirow[t]{2}{*}{ \# IFG } \\
\hline & Start & End & & & \\
\hline 010A_05426_030306 & 20150428 & 20200207 & 4.78 & 76 & 241 \\
\hline 010A_05549_121311 & 20151224 & 20200302 & 4.19 & 81 & 244 \\
\hline 017D_05353_130400 & 20151118 & 20200308 & 4.30 & 109 & 338 \\
\hline 017D_05514_131312 & 20141123 & 20200308 & 5.29 & 133 & 402 \\
\hline 039A_05193_040711 & 20150430 & 20200304 & 4.85 & 113 & 338 \\
\hline 039A_05372_151515 & 20150430 & 20200304 & 4.85 & 116 & 352 \\
\hline 046D_04690_121308 & 20141207 & 20200322 & 5.29 & 128 & 384 \\
\hline 046D_04907_081313 & 20141231 & 20200310 & 5.19 & 128 & 402 \\
\hline 046D_05096_121313 & 20141231 & 20200310 & 5.19 & 126 & 398 \\
\hline 046D_05292_131313 & 20141125 & 20200310 & 5.29 & 125 & 423 \\
\hline 046D_05469_071311 & 20141125 & 20200322 & 5.32 & 132 & 407 \\
\hline 054A_05688_051313 & 20150501 & 20200329 & 4.91 & 95 & 295 \\
\hline 054A_05884_001412 & 20150501 & 20200329 & 4.91 & 86 & 262 \\
\hline 068A_04667_071312 & 20150526 & 20200330 & 4.85 & 116 & 351 \\
\hline 083A_05460_050904 & 20150503 & 20200131 & 4.75 & 97 & 301 \\
\hline 083A_05602_131212 & 20151205 & 20200224 & 4.22 & 105 & 343 \\
\hline 090D_05485_121414 & 20151123 & 20200301 & 4.27 & 110 & 338 \\
\hline 090D_05651_051011 & 20141116 & 20200301 & 5.29 & 132 & 398 \\
\hline 112A_05300_030808 & 20150505 & 20200321 & 4.88 & 108 & 335 \\
\hline 112A_05454_131213 & 20150505 & 20200226 & 4.81 & 117 & 369 \\
\hline 119D_05226_070704 & 20150117 & 20200303 & 5.13 & 124 & 378 \\
\hline 119D_05372_141313 & 20150728 & 20200327 & 4.67 & 117 & 362 \\
\hline 119D_05525_040809 & 20141130 & 20200303 & 5.26 & 131 & 392 \\
\hline 127A_06256_070603 & 20160430 & 20200227 & 3.83 & 95 & 286 \\
\hline 141A_04925_131313 & 20150507 & 20200228 & 4.81 & 120 & 399 \\
\hline 141A_05118_131311 & 20150507 & 20200228 & 4.81 & 121 & 363 \\
\hline 141A_05337_160700 & 20151209 & 20200228 & 4.22 & 103 & 308 \\
\hline 148D_04631_101009 & 20141120 & 20200129 & 5.19 & 123 & 373 \\
\hline 156A_05639_121313 & 20150508 & 20200405 & 4.91 & 98 & 297 \\
\hline 156A_05796_080500 & 20150508 & 20200405 & 4.91 & 101 & 307 \\
\hline 163D_05579_100804 & 20141121 & 20200306 & 5.29 & 118 & 360 \\
\hline 163D_05736_131313 & 20141121 & 20200330 & 5.36 & 136 & 423 \\
\hline 163D_05934_091414 & 20141121 & 20200330 & 5.36 & 134 & 401 \\
\hline 170A_04675_131008 & 20160104 & 20200325 & 4.22 & 99 & 299 \\
\hline Total & & & & 3853 & 11,869 \\
\hline Average & & & & 113 & 349 \\
\hline
\end{tabular}

The tropospheric noise correction using the Generic Atmospheric Correction Online Service (GACOS) data (Yu et al. 2018) in step 0-3 was not applied except to data from Kanto (ID: 131) and Kumamoto (ID: 431) because the clipped areas were small enough to neglect the long-wavelength tropospheric noise and focus on flat areas where the topography-correlated stratified tropospheric noise is minimal (Figure S1). To reduce the impact of unwrapping errors in non-urban areas, pixels with an average coherence of $\leq 0.1$ in the unwrapped data were masked in step 0-4 before the subsequent time series analysis. Thereafter, all the unwrapped data and corresponding coherence images were clipped to the predefined areas in step 0-5 (Figs. 2 and S1; Table 2 ). The unwrapped coverage and coherence threshold in step $1-1$ were set to 0.5 and 0.06 , respectively. To mask noisy pixels based on several noise indices in step 1-5, strict thresholds to retain reliable pixels were set. The gap number threshold in the small baseline (SB) network was set to zero so that no gap was allowed in the network and the obtained time series was highly robust. The threshold numbers for loop error, maximum connected time length, and interferograms without loops were set to 3, 3 years, and 10, respectively. The temporal filter width in step 1-6 was set to 0.15 years (55 days), which is long enough compared to the sampling interval and short enough to retain seasonal components of the deformation time series. The default settings were used for other parameters. All parameter settings are listed in Table S1.

Kanto (ID: 131$)$ is very wide $(\sim 160 \mathrm{~km})$ and was significantly affected by long-wavelength postseismic deformation from the $2011 \mathrm{Mw} 9.0$ Tohoku earthquake (Suito 2018; Morishita et al. 2020). Because the purpose of this study is to measure localized urban ground deformation, deramping was applied with the best-fitting second order polynomial to remove the long-wavelength deformation component in step 1-6.

The Mw 7.0 Kumamoto earthquake occurred in Kumamoto (ID: 431) on April 16, 2016. Coseismic interferograms tend to be decorrelated due to very large surface deformation $(>2 \mathrm{~m})$ along the seismogenic Futagawa Fault, and they cause a gap in the SB network (Fujiwara et al. 2016; Himematsu and Furuya 2016; Kobayashi et al. 2019). To avoid the gap, interferograms from after the earthquake were used, as they detect postseismic deformation. The number of acquisitions before the earthquake was not sufficient for deriving reliable velocities and time series; thus, the pre-seismic data were not used in this study.

During the LiCSBAS processing, a primary stable reference point is automatically selected in step 1-6 as follows. The root mean square (RMS) of cumulative deformation time series after the spatio-temporal filter in step 1-6 at each pixel with reference to the median deformation for each epoch is calculated. Subsequently, a pixel with the minimum RMS is selected as a primary stable reference point. In this study, a common reference point for an area among different frames was further set to compare or combine the results from multiple frames 


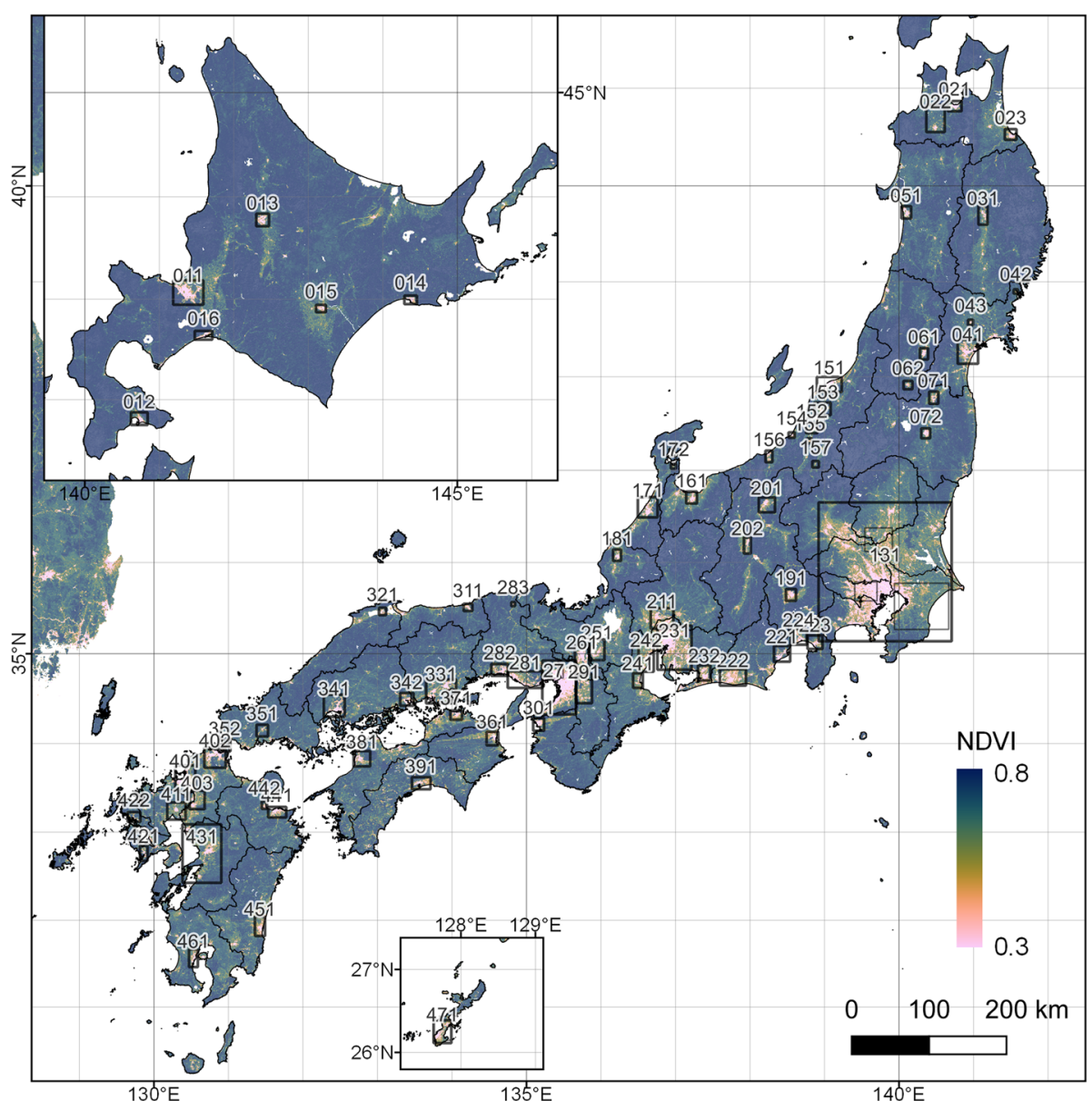

Fig. 2 A map of the clipped urban areas. Background colors denote NDVI in August 2012

by computing the average RMS among all available frames for an area and selecting a pixel with the minimum averaged RMS. Locations for a stable GNSS station outside of the significant deformation area were manually selected as the common reference point in Sanjo (ID: 153) and Kumamoto (ID: 431), because most of the processed area was deformed, and the automatically selected point was not stable.

The amplitude and time offset (i.e., phase) of annual sinusoidal components from the filtered deformation time series with the common reference point for each area were also estimated simultaneously with the velocity and constant term using least-squares (Morishita et al. 2020). Moreover, the multiple line-of-sight (LOS) velocities were decomposed into vertical and east-west (EW) components, neglecting north-south (NS) deformation because of low sensitivity to the NS component (Wright et al. 2004; Motagh et al. 2017; Fuhrmann and Garthwaite 2019).

Morishita et al. (2020) estimated the uncertainty of the deformation time series and velocities derived from LiCSBAS by comparing to GNSS and leveling and concluded that the accuracy was $<1 \mathrm{~cm} /$ epoch and $\sim 2$ $\mathrm{mm}$ /year with a 24-day interval and a time period longer than 2 years. Because the targets in this study were urban areas where interferometric coherence is generally high and severe thresholds are used for masking, the expected accuracy would be comparable to or better than $1 \mathrm{~cm} /$ epoch and $2 \mathrm{~mm} /$ year.

\section{Results}

Many deformation signals with various temporal features (i.e., linear, annual, episodic) were detected (Table 2; Figs. 3, 4, 5, 6, 7, 8, 9, 10, 11, 12, 13, 14 and 15 and S2S14). All figures including LOS velocities, amplitude, decomposed vertical and EW velocities, and processed data of all 191 data sets for 73 areas are available on an open repository (see "Availability of data and material").

In this section, subsidence signals seen in rice paddy fields are not discussed because they may not represent true deformation and result from systematic bias caused by fading signals (Ansari et al. 2020; see Section 4.1). Many subsidence signals were observed in reclaimed sites and mining areas as expected (e.g., 231 Nagoya, 341 
Table 2 Target urban areas, corresponding frame ID, and detected deformation signals

\begin{tabular}{|c|c|c|c|c|c|}
\hline \multirow{2}{*}{$\begin{array}{l}\text { Area } \\
\text { ID }\end{array}$} & \multirow{2}{*}{$\begin{array}{l}\text { Main city } \\
\text { name }\end{array}$} & \multicolumn{2}{|l|}{ Frame ID } & \multirow{2}{*}{$\begin{array}{l}\text { Detected } \\
\text { deformation }^{a}\end{array}$} & \multirow[t]{2}{*}{ Fig. } \\
\hline & & Ascending & Descending & & \\
\hline 011 & Sapporo & 068A_04667_071312 & 046D_04690_121308 & (S): 5 mm/year & \\
\hline 012 & Hakodate & 141A_04925_131313 & 046D_04907_081313 & & \\
\hline 013 & Asahikawa & $\begin{array}{l}\text { 170A_04675_131008 } \\
\text { 068A_04667_071312 }\end{array}$ & $\begin{array}{l}\text { 148D_04631_101009 } \\
\text { 046D_04690_121308 }\end{array}$ & & \\
\hline 014 & Kushiro & 170A_04675_131008 & 148D_04631_101009 & & \\
\hline 015 & Obihiro & $\begin{array}{l}\text { 170A_04675_131008 } \\
\text { 068A_04667_071312 }\end{array}$ & 148D_04631_101009 & & \\
\hline 016 & Tomakomai & 068A_04667_071312 & 046D_04690_121308 & (S): 10 mm/year & S2 \\
\hline 021 & Aomori & 141A_04925_131313 & 046D_04907_081313 & $\mathrm{S}: 5 \mathrm{~mm} /$ year & \\
\hline 022 & Hirosaki & 141A_04925_131313 & 046D_04907_081313 & $\begin{array}{l}\text { (S): } 40 \mathrm{~mm} / \text { year } \\
\mathrm{A}: 15 \mathrm{~mm} \text {, Feb }\end{array}$ & $\begin{array}{l}10,16 \\
\text { S10 }\end{array}$ \\
\hline 023 & Hachinohe & 141A_04925_131313 & 046D_04907_081313 & & \\
\hline 031 & Morioka & 141A_05118_131311 & 046D_05096_121313 & & \\
\hline 041 & Sendai & 141A_05118_131311 & 046D_05096_121313 & & \\
\hline 042 & Kesennuma & 141A_05118_131311 & 046D_05096_121313 & (S): $10 \mathrm{~mm} /$ year & S3 \\
\hline 043 & Osaki & 141A_05118_131311 & 046D_05096_121313 & & \\
\hline 051 & Akita & 141A_04925_131313 & 046D_05096_121313 & & \\
\hline 061 & Yamagata & 141A_05118_131311 & 046D_05096_121313 & $\begin{array}{l}\text { S: } 5 \mathrm{~mm} / \text { year } \\
\text { A: } 5 \mathrm{~mm} \text {, Mar }\end{array}$ & 6,57 \\
\hline 062 & Yonezawa & $\begin{array}{l}\text { 141A_05118_131311 } \\
\text { 039A_05193_040711 }\end{array}$ & 046D_05292_131313 & A: $15 \mathrm{~mm}$, Mar & 7,58 \\
\hline 071 & Fukushima & 141A_05118_131311 & 046D_05292_131313 & & \\
\hline 072 & Koriyama & $\begin{array}{l}\text { 141A_05337_160700 } \\
\text { 039A_05372_151515 }\end{array}$ & 046D_05292_131313 & & \\
\hline 131 & $\begin{array}{l}\text { Kanto (Tokyo) } \\
\text { - Kyujukuri } \\
\text { - Nogi } \\
\text { - Chofu }\end{array}$ & $\begin{array}{l}\text { 141A_05337_160700 } \\
\text { 039A_05372_151515 }\end{array}$ & $\begin{array}{l}\text { 046D_05469_071311 } \\
\text { 046D_05292_131313 }\end{array}$ & $\begin{array}{l}\text { S: } 10 \mathrm{~mm} / \text { year } \\
\text { (S): } 20 \mathrm{~mm} / \text { year } \\
\text { A: } 10 \mathrm{~mm} \text {, Jul } \\
\text { U: } 5 \mathrm{~mm} / \text { year }\end{array}$ & $\begin{array}{l}54 \\
3 \\
9 \\
12\end{array}$ \\
\hline 151 & Niigata & 039A_05193_040711 & $\begin{array}{l}\text { 119D_05226_070704 } \\
\text { 046D_05292_131313 }\end{array}$ & $\mathrm{S}: 15 \mathrm{~mm} /$ year & 4,55 \\
\hline 152 & Nagaoka & 039A_05193_040711 & $\begin{array}{l}\text { 119D_05226_070704 } \\
\text { 046D_05292_131313 }\end{array}$ & $\begin{array}{l}\text { (S): } 5 \mathrm{~mm} / \text { year } \\
\text { A: } 10 \mathrm{~mm} \text {, Mar }\end{array}$ & \\
\hline 153 & Sanjo & 039A_05193_040711 & $\begin{array}{l}\text { 119D_05226_070704 } \\
\text { 046D_05292_131313 }\end{array}$ & $\begin{array}{l}\text { S: } 25 \mathrm{~mm} / \text { year } \\
\text { A: } 10 \mathrm{~mm} \text {, Apr }\end{array}$ & $11, \mathrm{~S} 11$ \\
\hline 154 & Kashiwazaki & 039A_05193_040711 & 119D_05226_070704 & $\mathrm{S}: 5 \mathrm{~mm} /$ year & \\
\hline 155 & Ojiya & 039A_05372_151515 & $\begin{array}{l}\text { 119D_05226_070704 } \\
\text { 046D_05292_131313 }\end{array}$ & A: $20 \mathrm{~mm}$, Mar & 8,59 \\
\hline 156 & Joetsu & $\begin{array}{l}\text { 112A_05300_030808 } \\
\text { 039A_05372_151515 }\end{array}$ & 119D_05372_141313 & & \\
\hline 157 & Minamiuonuma & 039A_05372_151515 & $\begin{array}{l}\text { 119D_05372_141313 } \\
\text { 046D_05292_131313 }\end{array}$ & A: 5 mm, Feb & \\
\hline 161 & Toyama & 112A_05300_030808 & $\begin{array}{l}\text { 119D_05372_141313 } \\
\text { 017D_05353_130400 }\end{array}$ & & \\
\hline 171 & Kanazawa & 112A_05300_030808 & $\begin{array}{l}\text { 119D_05372_141313 } \\
\text { 017D_05353_130400 }\end{array}$ & $\mathrm{S}: 10 \mathrm{~mm} /$ year & 5,56 \\
\hline 172 & Nanao & 112A_05300_030808 & $\begin{array}{l}\text { 119D_05372_141313 } \\
\text { 017D_05353_130400 }\end{array}$ & & \\
\hline 181 & Fukui & $\begin{array}{l}\text { 112A_05454_131213 } \\
\text { 010A_05426_030306 }\end{array}$ & 017D_05353_130400 & & \\
\hline
\end{tabular}


Table 2 Target urban areas, corresponding frame ID, and detected deformation signals (Continued)

\begin{tabular}{|c|c|c|c|c|c|}
\hline \multirow{2}{*}{$\begin{array}{l}\text { Area } \\
\text { ID }\end{array}$} & \multirow{2}{*}{$\begin{array}{l}\text { Main city } \\
\text { name }\end{array}$} & \multicolumn{2}{|l|}{ Frame ID } & \multirow{2}{*}{$\begin{array}{l}\text { Detected } \\
\text { deformation }^{a}\end{array}$} & \multirow[t]{2}{*}{ Fig. } \\
\hline & & Ascending & Descending & & \\
\hline 191 & Kofu & $\begin{array}{l}\text { 112A_05454_131213 } \\
\text { 039A_05372_151515 }\end{array}$ & $\begin{array}{l}\text { 119D_05372_141313 } \\
\text { 046D_05469_071311 }\end{array}$ & & \\
\hline 201 & Nagano & $\begin{array}{l}\text { 112A_05454_131213 } \\
\text { 039A_05372_151515 }\end{array}$ & 119D_05372_141313 & (S): 10 mm/year & \\
\hline 202 & Matsumoto & $\begin{array}{l}\text { 112A_05454_131213 } \\
\text { 039A_05372_151515 }\end{array}$ & 119D_05372_141313 & & \\
\hline 211 & Gifu & 112A_05454_131213 & $\begin{array}{l}\text { 119D_05372_141313 } \\
\text { 017D_05514_131312 }\end{array}$ & & \\
\hline 221 & Shizuoka & $\begin{array}{l}\text { 112A_05454_131213 } \\
\text { 039A_05372_151515 }\end{array}$ & $\begin{array}{l}\text { 119D_05525_040809 } \\
\text { 046D_05469_071311 }\end{array}$ & (S): $5 \mathrm{~mm} /$ year & \\
\hline 222 & Hamamatsu & 112A_05454_131213 & 119D_05525_040809 & (S): 15 mm/year & \\
\hline 223 & Numazu & 039A_05372_151515 & $\begin{array}{l}\text { 119D_05372_141313 } \\
\text { 046D_05469_071311 }\end{array}$ & (S): 5 mm/year & \\
\hline 224 & Fuji & $\begin{array}{l}\text { 112A_05454_131213 } \\
\text { 039A_05372_151515 }\end{array}$ & $\begin{array}{l}\text { 119D_05372_141313 } \\
\text { 046D_05469_071311 }\end{array}$ & (S): 5 mm/year & \\
\hline 231 & Nagoya & 112A_05454_131213 & 119D_05525_040809 & (S): 15 mm/year & \\
\hline 232 & Toyohashi & 112A_05454_131213 & 119D_05525_040809 & & \\
\hline 241 & Tsu & $\begin{array}{l}\text { 112A_05454_131213 } \\
\text { 010A_05549_121311 }\end{array}$ & $\begin{array}{l}\text { 119D_05525_040809 } \\
\text { 017D_05514_131312 }\end{array}$ & (S): 5 mm/year & 16 \\
\hline 242 & Yokkaichi & $\begin{array}{l}\text { 112A_05454_131213 } \\
\text { 010A_05549_121311 }\end{array}$ & $\begin{array}{l}\text { 119D_05525_040809 } \\
\text { 017D_05514_131312 }\end{array}$ & (S): $5 \mathrm{~mm} /$ year & \\
\hline 251 & Otsu & 010A_05549_121311 & 017D_05514_131312 & (S): 5 mm/year & \\
\hline 261 & Kyoto & 010A_05549_121311 & 017D_05514_131312 & (S): $15 \mathrm{~mm} /$ year & \\
\hline 271 & Osaka & 010A_05549_121311 & 017D_05514_131312 & $\begin{array}{l}\text { (S): } 15 \mathrm{~mm} / \text { year } \\
\text { U: } 5 \mathrm{~mm} / \text { year } \\
\text { A: } 5 \mathrm{~mm} \text {, Jul }\end{array}$ & $14, S 13$ \\
\hline 281 & Kobe & 010A_05549_121311 & 017D_05514_131312 & 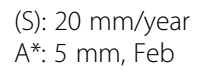 & \\
\hline 282 & Himeji & $\begin{array}{l}\text { 083A_05602_131212 } \\
\text { 010A_05549_121311 }\end{array}$ & $\begin{array}{l}\text { 090D_05485_121414 } \\
\text { 017D_05514_131312 }\end{array}$ & $\mathrm{S}: 5 \mathrm{~mm} /$ year & \\
\hline 283 & Toyooka & 010A_05426_030306 & $\begin{array}{l}\text { 090D_05485_121414 } \\
\text { 017D_05514_131312 }\end{array}$ & & \\
\hline 291 & Nara & 010A_05549_121311 & 017D_05514_131312 & $\mathrm{U}: 5 \mathrm{~mm} /$ year & $13, S 12$ \\
\hline 301 & Wakayama & 010A_05549_121311 & 017D_05514_131312 & (S): $5 \mathrm{~mm} /$ year & \\
\hline 311 & Tottori & $\begin{array}{l}\text { 083A_05460_050904 } \\
\text { 010A_05426_030306 }\end{array}$ & $\begin{array}{l}\text { 090D_05485_121414 } \\
\text { 017D_05514_131312 }\end{array}$ & & \\
\hline 321 & Matsue & 083A_05460_050904 & 090D_05485_121414 & & \\
\hline 331 & Okayama & 083A_05602_131212 & 090D_05485_121414 & & \\
\hline 341 & Hiroshima & $\begin{array}{l}\text { 083A_05602_131212 } \\
\text { 156A_05639_121313 }\end{array}$ & $\begin{array}{l}\text { 090D_05485_121414 } \\
\text { 163D_05579_100804 }\end{array}$ & $\begin{array}{l}\text { (S): } 10 \mathrm{~mm} / \text { year } \\
\mathrm{A}^{*}: 5 \mathrm{~mm} \text {, Feb }\end{array}$ & \\
\hline 342 & Fukuyama & 083A_05602_131212 & 090D_05485_121414 & (S): 30 mm/year & \\
\hline 351 & Yamaguchi & 156A_05639_121313 & 163D_05579_100804 & & \\
\hline 352 & Shimonoseki & 156A_05639_121313 & 163D_05579_100804 & (S): 5 mm/year & \\
\hline 361 & Tokushima & $\begin{array}{l}\text { 083A_05602_131212 } \\
\text { 010A_05549_121311 }\end{array}$ & $\begin{array}{l}\text { 090D_05485_121414 } \\
\text { 017D_05514_131312 }\end{array}$ & (S): $5 \mathrm{~mm} /$ year & \\
\hline 371 & Takamatsu & 083A_05602_131212 & $\begin{array}{l}\text { 090D_05485_121414 } \\
\text { 017D_05514_131312 }\end{array}$ & & \\
\hline 381 & Matsuyama & $\begin{array}{l}\text { 083A_05602_131212 } \\
\text { 156A_05639_121313 }\end{array}$ & 090D_05651_051011 & & \\
\hline
\end{tabular}


Table 2 Target urban areas, corresponding frame ID, and detected deformation signals (Continued)

\begin{tabular}{|c|c|c|c|c|c|}
\hline \multirow{2}{*}{$\begin{array}{l}\text { Area } \\
\text { ID }\end{array}$} & \multirow{2}{*}{$\begin{array}{l}\text { Main city } \\
\text { name }\end{array}$} & \multicolumn{2}{|l|}{ Frame ID } & \multirow{2}{*}{$\begin{array}{l}\text { Detected } \\
\text { deformation }^{a}\end{array}$} & \multirow[t]{2}{*}{ Fig. } \\
\hline & & Ascending & Descending & & \\
\hline 391 & Kochi & 083A_05602_131212 & 090D_05651_051011 & & \\
\hline 401 & Fukuoka & $\begin{array}{l}\text { 054A_05688_051313 } \\
\text { 156A_05639_121313 }\end{array}$ & 163D_05736_131313 & (S): 10 mm/year & \\
\hline 402 & Kitakyushu & 156A_05639_121313 & 163D_05579_100804 & (S): 5 mm/year & \\
\hline 403 & Kurume & $\begin{array}{l}\text { 054A_05688_051313 } \\
\text { 156A_05639_121313 }\end{array}$ & 163D_05736_131313 & (S): 5 mm/year & \\
\hline 411 & Saga & $\begin{array}{l}\text { 054A_05688_051313 } \\
\text { 156A_05639_121313 }\end{array}$ & 163D_05736_131313 & & \\
\hline 421 & Nagasaki & 054A_05688_051313 & 163D_05736_131313 & 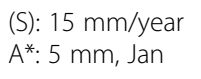 & \\
\hline 422 & Sasebo & 054A_05688_051313 & 163D_05736_131313 & (S): 5 mm/year & \\
\hline 431 & Kumamoto $^{b}$ & $\begin{array}{l}\text { 054A_05688_051313 } \\
\text { 156A_05639_121313 }\end{array}$ & 163D_05736_131313 & $\begin{array}{l}\text { P: } 25 \mathrm{~mm} / \text { year } \\
\text { A: } 5 \mathrm{~mm} \text {, Sep }\end{array}$ & $15, S 14$ \\
\hline 441 & Oita & 156A_05639_121313 & 163D_05736_131313 & $\mathrm{S}: 5 \mathrm{~mm} /$ year & \\
\hline 442 & Beppu & 156A_05639_121313 & 163D_05736_131313 & S: 5 mm/year & \\
\hline 451 & Miyazaki & 156A_05796_080500 & 163D_05736_131313 & (S): 10 mm/year & \\
\hline 461 & Kagoshima & 054A_05884_001412 & 163D_05934_091414 & & \\
\hline 471 & Naha & 127A_06256_070603 & -- & (S): 10 mm/year & \\
\hline
\end{tabular}

$\mathrm{A}^{*}$ : Annual fluctuation presumably caused by the atmospheric noise

Months of annual fluctuation indicate time of the negative (subsidence) peaks

${ }^{a} A$ annual fluctuation, $P$ postseismic deformation, $S$ subsidence, $(S)$ subsidence only outside of DID and rice paddy fields, $U$ uplift

${ }^{b}$ Only postseismic data (after April 16, 2016) were used

Hiroshima, 342 Fukuyama). Some industrial zones also showed subsidence, probably due to heavy groundwater usage (e.g., 016 Tomakomai and 042 Kesennuma; Figures S2 and S3). Cities on the Pacific side of the Tohoku region (041 Sendai, 071 Fukushima, 072 Koriyama) tended to show broad eastern uplift, likely due to the postseismic deformation of the $2011 \mathrm{Mw} 9.0$ Tohoku earthquake (Suito 2018). Subsidence, uplift, and annual fluctuations in DID presumably associated with groundwater or natural gas were observed in approximately 10 ,
10 , and 3 areas, respectively, and the details of some of the significant cases are described in the following subsections.

As the observed subsidence in urban areas is slow ( $\leq$ $15 \mathrm{~mm} /$ year except for Sanjo), and only four areas have the rate of $\geq 10 \mathrm{~mm} /$ year, overall subsidence in Japan seems to be quite inactive due to strict regulations on groundwater usage (Table 2). Other nationwide studies using InSAR detected rapid subsidence in developing countries, such as Indonesia $(8-22 \mathrm{~cm} /$ year; Chaussard

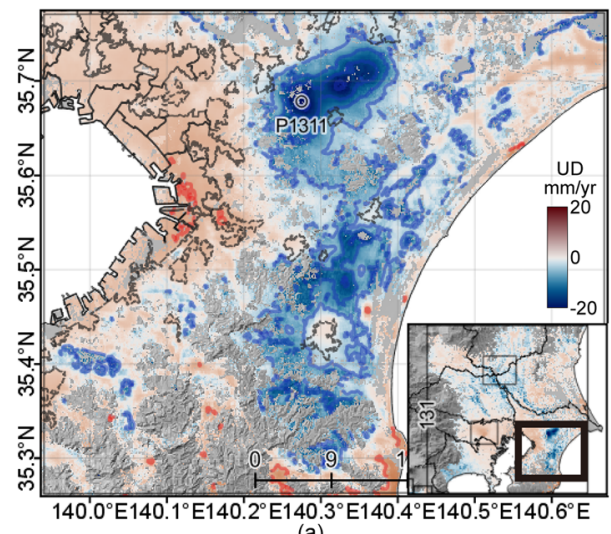

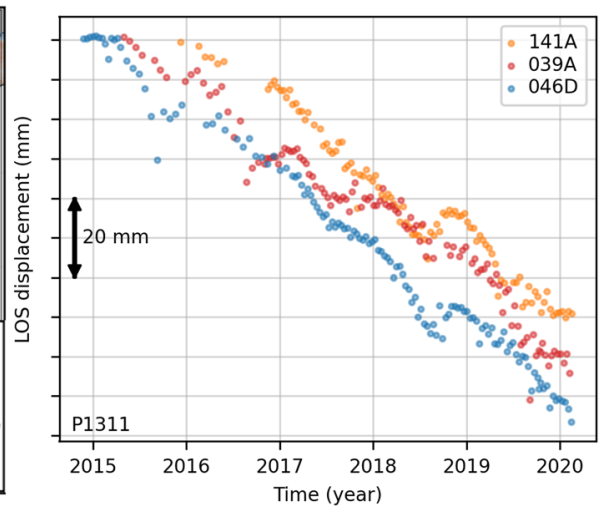

(b)

Fig. 3 a Vertical deformation velocities in Kujyukuri (ID: 131, Kanto). The black lines denote the outlines of the DID. The interval of the red (uplift) and blue (subsidence) contour lines is $5 \mathrm{~mm} /$ year without the $0 \mathrm{~mm} / \mathrm{year}$ lines. The inset denotes the whole area of the $131 \mathrm{Kanto}$. $\mathbf{b}$ LOS deformation time series at P1311 for each frame 


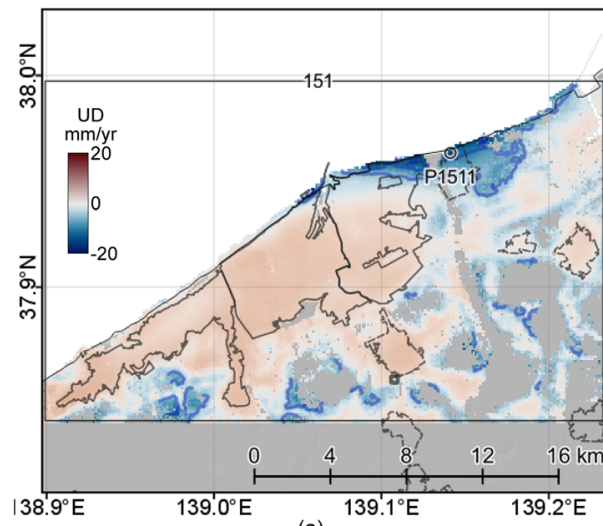

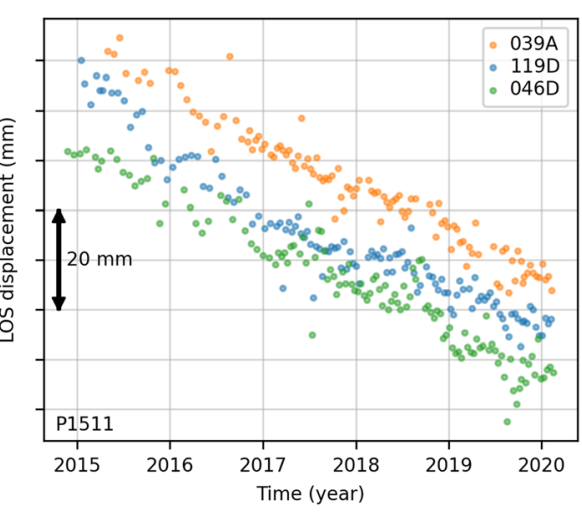

(b)

Fig. 4 a Vertical deformation velocities in Niigata (ID: 151). The black lines denote the outlines of the DID. The interval of the blue (subsidence) contour lines is $5 \mathrm{~mm} /$ year without the $0 \mathrm{~mm} /$ year lines. The black square denotes the reference point. (b) LOS deformation time series at P1511 for each frame

et al. 2013), Mexico (5-30 cm/year; Chaussard et al. 2014), and Turkey (> $5 \mathrm{~cm} /$ year; Weiss et al. 2020), and slow subsidence in developed countries, such as Italy ( $2 \mathrm{~cm} /$ year; Manunta et al. 2019) and California in the USA $(<1 \mathrm{~cm} /$ year; Blackwell et al. 2020). Thus, the subsidence conditions in Japan are similar to those in other developed countries.

\subsection{Linear subsidence $\geq 10 \mathrm{~mm} /$ year}

Significant subsidence ( $\geq 10 \mathrm{~mm} /$ year) was detected in Kujyukuri, (ID: 131, Chiba in Kanto; 20 mm/year; Figs. 3 and S4), Niigata (ID: 151; $15 \mathrm{~mm} /$ year; Figs. 4 and S5), and Kanazawa (ID: 171 ; $10 \mathrm{~mm} /$ year; Figs. 5 and S6). Although subsidence in these areas has been well studied and monitored by leveling surveys, groundwater observation wells, and InSAR (e.g., Shen et al. 2004; Ministry of the Environment 2019; Nonaka et al. 2020; Morishita et al. 2020), the detailed spatial and/or temporal features were unclear. However, the results in this study revealed detailed spatial distribution (e.g., peak locations and shape of the subsiding area) and almost linear temporal subsidence evolution.

\subsection{Annual vertical fluctuation}

Annual vertical fluctuations were observed in Yamagata (ID: 061; amplitude of $\sim 5 \mathrm{~mm}$; Figs. 6 and S7), Yonezawa (ID: 062; amplitude of $\sim 15 \mathrm{~mm}$; Figs. 7 and S8), Ojiya (ID: 155; amplitude of $\sim 20 \mathrm{~mm}$; Figs. 8 and S9), and Nogi (ID: 131, Tochigi in Kanto; amplitude of $\sim 10$ $\mathrm{mm}$; Figs. 9 and S4). Yamagata had slight linear subsidence $(\sim 5 \mathrm{~mm} /$ year $)$ as well, while the other areas showed no significant subsidence. All areas except Nogi had negative (subsidence) peaks in winter (around February or March) and substantial snow (Table 2). Therefore, the seasonal subsidence is likely attributed to the
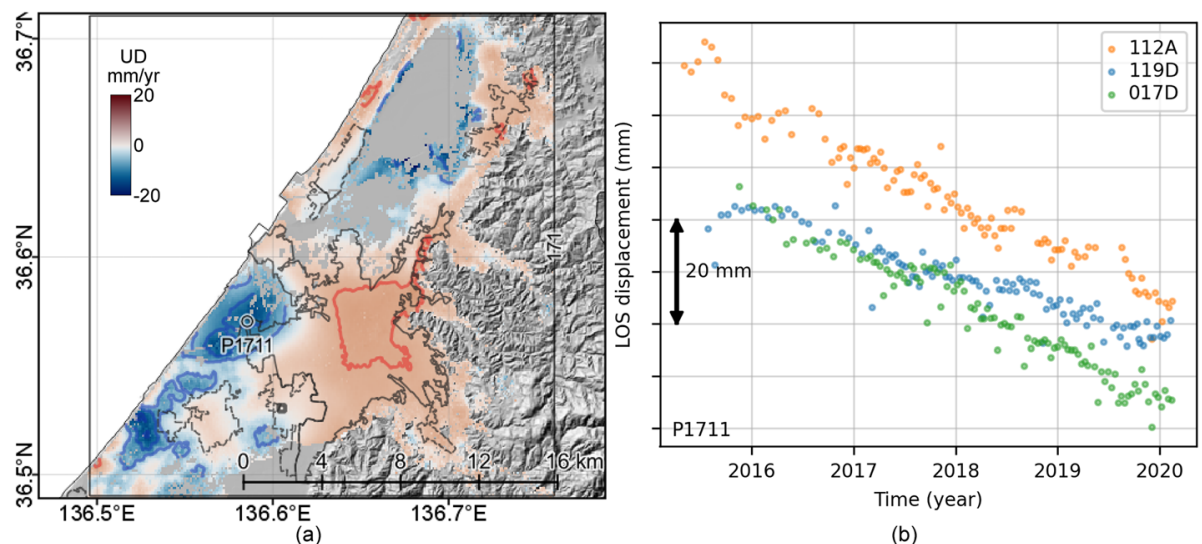

(b)

Fig. 5 a Vertical deformation velocities in Kanazawa (ID: 171). The black lines denote the outlines of the DID. The interval of the red (uplift) and blue (subsidence) contour lines is $5 \mathrm{~mm} /$ year without the $0 \mathrm{~mm} /$ year lines. The black square denotes the reference point. b LOS deformation time series at P1711 for each frame 


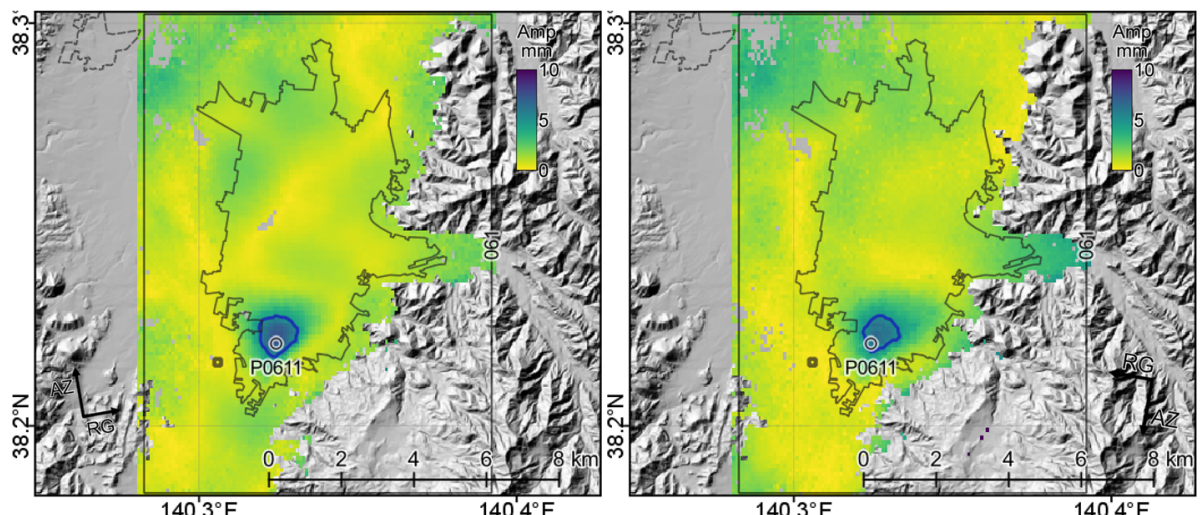

(a)

(b)
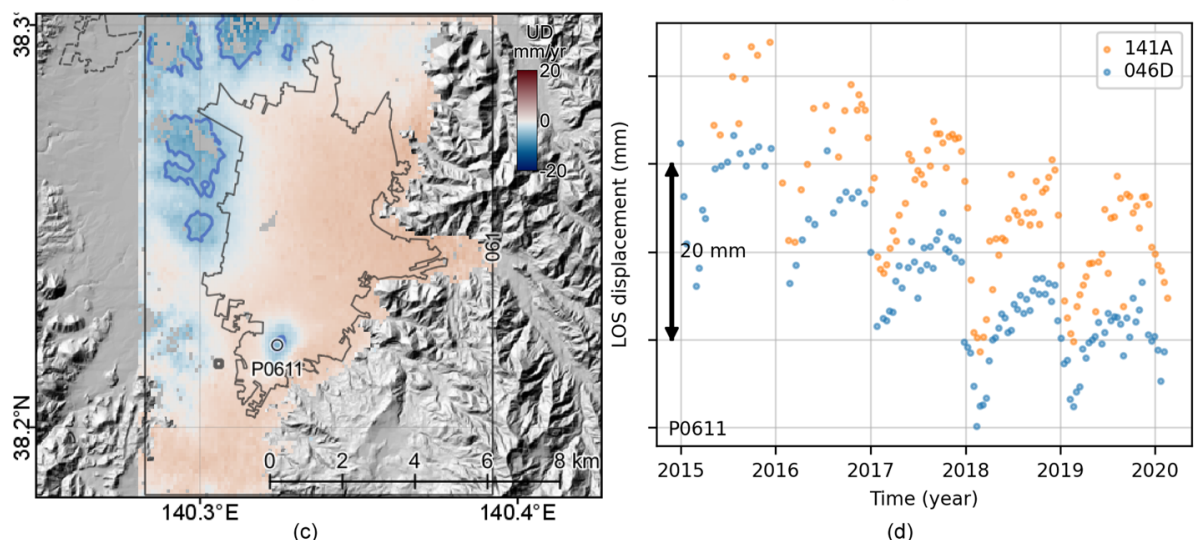

(d)

Fig. 6 a Amplitudes of the annual LOS fluctuation in Yamagata (ID: 061) from the ascending 141A_05118_131311. The black lines denote the outlines of the DID. The interval of the contour lines is $5 \mathrm{~mm}$. The black square denotes the reference point. $\mathbf{b}$ Amplitudes from the descending 046D_05096_121313. c Vertical deformation velocities. The interval of the blue (subsidence) contour lines is $5 \mathrm{~mm} /$ year without the $0 \mathrm{~mm} / \mathrm{year}$ lines. $\mathbf{d}$ LOS deformation time series at P0611 for each frame

groundwater usage for snow melting (Sato et al. 2003; Morishita et al. 2020).

In contrast, Nogi had the opposite seasonal component; negative (subsidence) peaks in summer. Settlement and groundwater gauges also measured the consistent seasonal fluctuations, and the subsidence signals in summer were considered to be caused by high summer agricultural groundwater usage (Tochigi Prefecture 2011). Considerably large amounts of subsidence $(\sim 70 \mathrm{~cm})$ occurred from 1977 to 1997 in Nogi, although the subsidence speed has since decelerated, and almost no subsidence has been detected recently (Tochigi Prefecture 2011). In 1996, this area had a severe drought and experienced the largest amount of subsidence in Japan measured by leveling surveys and JERS-1 InSAR (Nakagawa et al. 2000). This implies that this area has contraction-prone soil layers.

\subsection{Fast linear subsidence and segregated annual fluctuation in Hirosaki}

Fast subsidence $(\sim 40 \mathrm{~mm} /$ year $)$ was detected by the ALOS data in 2007-2009 in the Hirosaki plain (ID: 022;
Morishita et al. 2010). Most of this area is covered with light vegetation, and several unwrapping errors exist especially in the descending LiCSAR products. The masking step in LiCSBAS (step 1-5) returned too sparse a result to capture the entire deformation signal (Figure S10a); therefore, unmasked results were used here. They contain more noise than the masked ones; however, the subsidence signals were still larger than the unmasked noise, as shown below.

Two rapid subsidence basins were found outside of the DID in the Hirosaki plain $(\sim 40 \mathrm{~mm} /$ year; Fig. 10a). They had contractional EW components as well as large vertical components, as expected for a subsidence basin (Fig. 10b; Samieie-Esfahany et al. 2009; Fuhrmann and Garthwaite 2019). The deformation time series at P0221 and P0222 indicated almost linear subsidence (Fig. 10e). Interestingly, a significant annual component (amplitude of $\sim 15 \mathrm{~mm}$ ) was detected in the northern DID (Goshogawara City, P0223) adjacent to the northern subsidence basin (Fig. 10c, d). The time series showed that the negative (subsidence) peaks occurred in winter, as in cities 


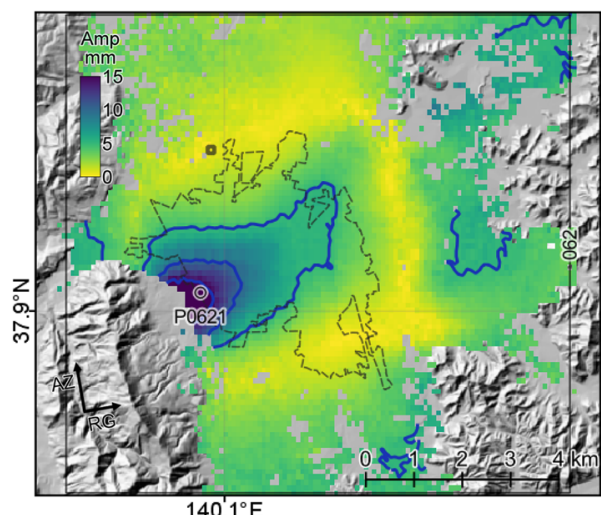

(a)

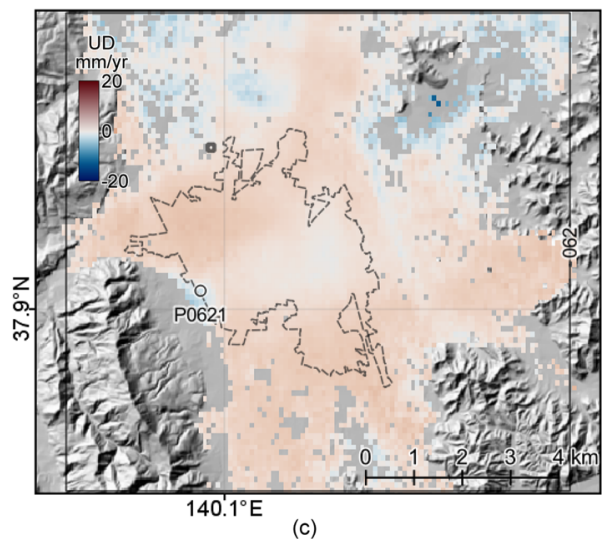

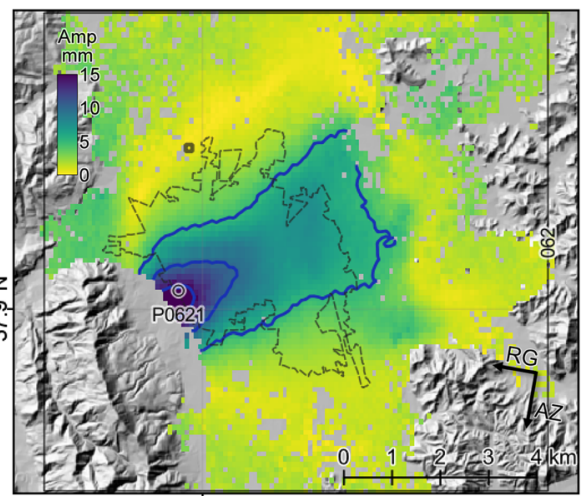

(b)

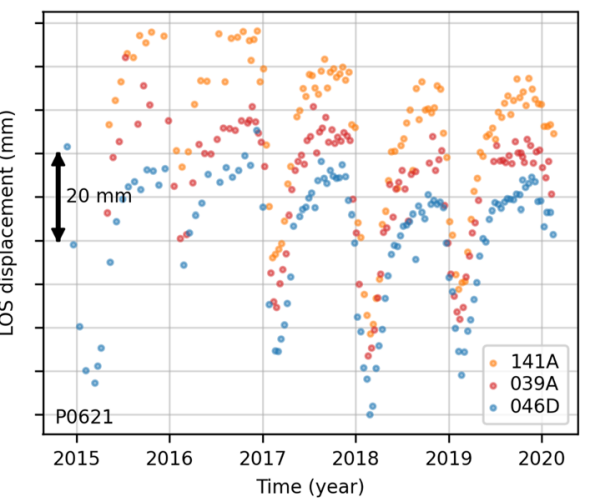

(d)

Fig. 7 a Amplitudes of the annual LOS fluctuation in Yonezawa (ID: 062) from the ascending 141A_05118_131311. The black lines denote the outlines of the DID. The interval of the contour lines is $5 \mathrm{~mm}$. The black square denotes the reference point. $\mathbf{b}$ Amplitudes from the descending 046D_05096_121313. c Vertical deformation velocities. $\mathbf{d}$ LOS deformation time series at P0621 for each frame

shown in the previous subsection, which implies this annual deformation is also attributed to the groundwater usage for snow melting.

\subsection{Episodic subsidence in Sanjo}

Morishita et al. (2020) detected $\sim 4 \mathrm{~cm}$ episodic subsidence in the winter of 2017/2018 in Sanjo (ID: 153), likely caused by unusually heavy snowfall and related over pumping of groundwater, as well as annual components of negative (subsidence) peaks in winter. Here, three independent data sets (one ascending and two descending) are available and showed consistent measurements of the episodic subsidence and annual components (Figs. 11 and S11). Notably, the time series at P1531 potentially indicated a slight uplift tendency after the episodic subsidence in the winter of $2017 / 2018$. Continual monitoring will reveal whether the subsided ground surface is rebounding or not over a longer timeframe.

\subsection{Linear uplift in Chofu, Kanto}

While uplift signals were rarely observed in this study, Chofu (ID: 131, Tokyo in Kanto; Figs. 12a and S4) data showed slow uplift ( $\sim \mathrm{mm} /$ year). To minimize the atmospheric noise contribution and obtain the precise time series, I manually set the reference point near the uplift region for the time series plot (P1313ref). The time series at P1313 indicates that the uplift rate was nearly constant (Fig. 12b). The Tokyo Metropolitan Government (2019) reported that the groundwater level is rising, and uplift has been observed by leveling in this area. The shape of the uplift was not isotropic; a V-shaped edge with relatively large deformation gradient was seen in the southern uplift area, which might be controlled by subsurface geological boundaries.

\subsection{Nonlinear uplift in Nara}

Two distinct small uplift signals with a distance of $\sim 10$ km (P2911 and P2912) were detected in the Nara prefecture (ID: 291; Figs. 13a and S12). Because the EW deformation component also showed small horizontal extension (Fig. 13b), and the deformation areas were not correlated with Normalized Difference Vegetation Index (NDVI; i.e., the land use; Fig. 13c) or topography (Figure $\mathrm{S} 12 \mathrm{~b})$, the deformation source was not on the surface 


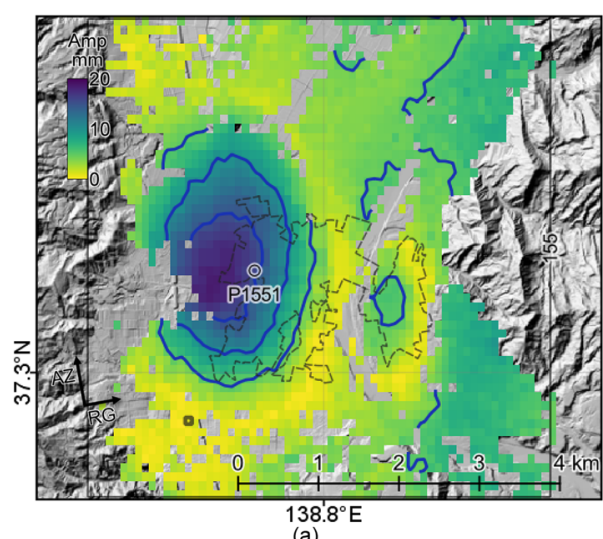

(a)

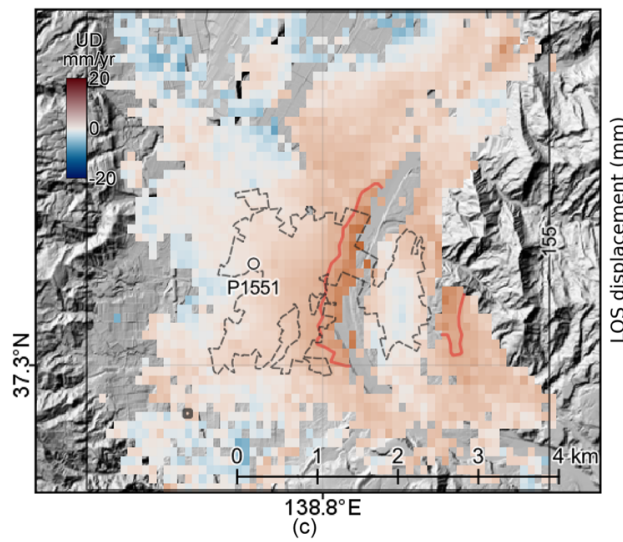

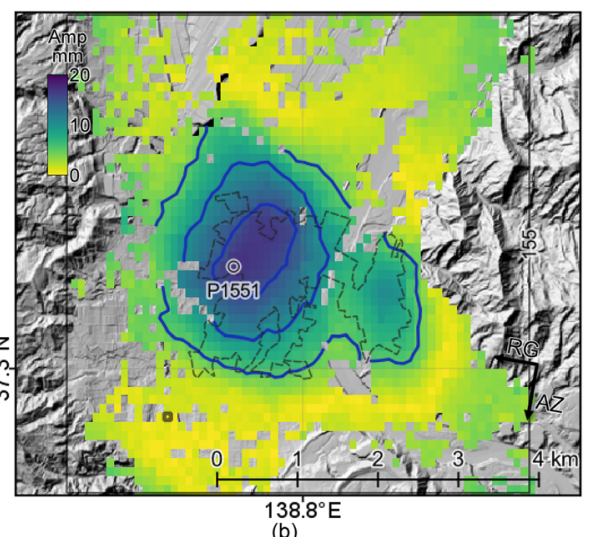

(b)

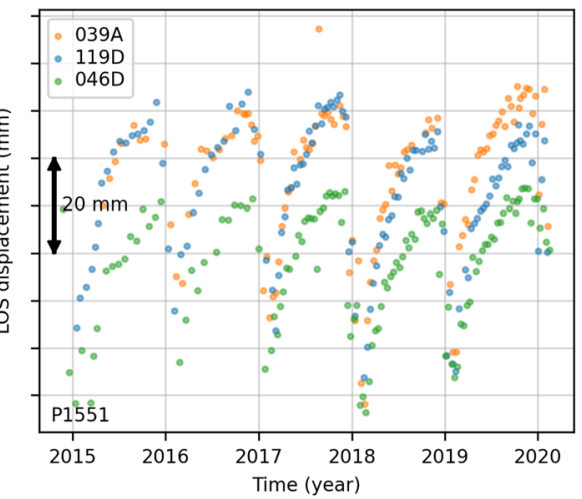

(d)

Fig. 8 a Amplitudes of the annual LOS fluctuation in Ojiya (ID: 155) from the ascending 039A_05372_151515. The black lines denote the outlines of the DID. The interval of the contour lines is $5 \mathrm{~mm}$. The black square denotes the reference point. $\mathbf{b}$ Amplitudes from the descending 119D_05226_070704. c Vertical deformation velocities. The interval of the red (uplift) contour lines is $5 \mathrm{~mm} /$ year without the $0 \mathrm{~mm} / \mathrm{year}$ lines. $\mathbf{d}$ LOS deformation time series at P1551 for each frame

but at depth. The deformation time series showed approximately $1 \mathrm{~cm}$ of nonlinear uplift in 2018 in both areas (Fig. 13d). The uplift timing at the western P2912 seemed to be a few months earlier than that of the eastern P2911. These facts suggest that the uplift signal sources may not be common, but are related.

In this area, no earthquakes with $>\mathrm{Mw} 3.5$ and depth of $<50 \mathrm{~km}$ occurred during the observation period of Sentinel-1 (Japan Meteorological Agency 2020). No active volcanoes or known faults were around. It is unlikely that these uplift signals stemmed from atmospheric noise, because the spatial extent is only $\sim 2 \mathrm{~km}$ and $\sim 5 \mathrm{~km}$, and the deformation time series showed clear temporal correlation. Currently, the sources of these nonlinear uplift signals are unknown, and further investigation is required.

\subsection{Nonlinear uplift and annual fluctuation between faults in Osaka}

In the northern part of the Osaka prefecture, the Arima-Takatsuki fault zone and Rokko-Awaji fault zone are nearly parallel and form a triangular zone between them (The Headquarters for Earthquake Research Promotion 2020a, 2020b; Fig. 14a). In this study, a small uplift signal with an extent of $\sim 3 \mathrm{~km}$ was found in the western edge of the triangle zone, accompanying small westward deformation (Figs. 14a, b and S13). The deformation time series at P2711 showed $\sim 1.5 \mathrm{~cm}$ nonlinear uplift in 2018, which resembles signals from a slow slip event on a fault (Fig. 14f). Adjacent to the uplift zone, an area with relatively large annual deformation exists in the east (Fig. 14c, d, f). As these areas are highly urbanized (Fig. 14e), the deformation time series should be very accurate.

Hashimoto (2016) revealed the deformation history in the triangle zone from 1992 to 2010 using various SAR data. After the $1995 \mathrm{Mw} 6.8$ Kobe earthquake, subsidence started throughout the zone. The subsidence became concentrated in two spots, accelerating after 2003, and lasting at least until 2010. The western spot is adjacent to the deforming zones detected in this study (Fig. 14). The deformation style changed with each decade, among small blocks with the width of a few $\mathrm{km}$ in the 

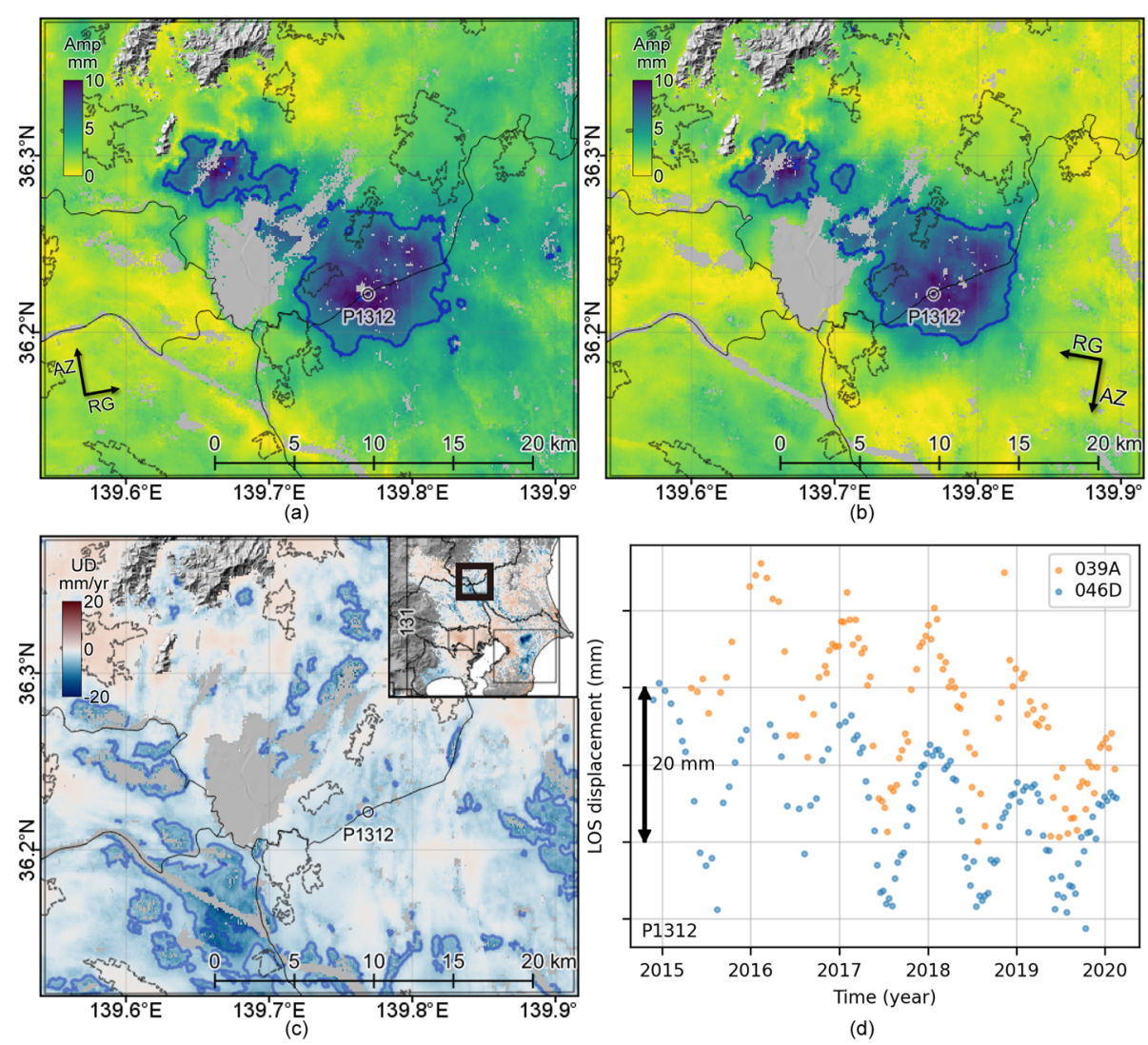

(d)

Fig. 9 a Amplitudes of the annual LOS fluctuation in Nogi (ID: 131, Tochigi in Kanto) from the ascending 039A_05372_151515. The black lines denote the borders between prefectures. The interval of the contour lines is $5 \mathrm{~mm}$. b Amplitudes from the descending 046D_05292_131313. c Vertical deformation velocities. The interval of the blue (subsidence) contour lines is $5 \mathrm{~mm} / \mathrm{year}$ without the $0 \mathrm{~mm} / \mathrm{year}$ lines. The inset denotes the whole area of the 131 Kanto. $\mathbf{d}$ LOS deformation time series at P1312 for each frame

triangle zone. The mechanism of these varying deformations, whether related to groundwater or tectonic activity, is not clear.

On June 18, 2018, a Mw 5.6 earthquake with a depth of $13 \mathrm{~km}$ occurred $25 \mathrm{~km}$ east of the triangle zone along the Arima-Takatsuki fault zone (Fig. 14a). While significant coseismic deformation was not detected, a small and shallow slip may have been triggered along the fault zone (Fujiwara et al. 2020). However, considering the temporal feature of the uplift in the triangle zone and its long distance from the epicenter and shallow slip, there seems to be no direct relationship between the earthquake and the uplift.

\subsection{Postseismic deformation of the 2016 Kumamoto earthquake}

The Mw 7.0 Kumamoto earthquake occurred on April 16,2016 , and associated large coseismic deformation $(>2 \mathrm{~m})$ and small displacement lineaments were observed around the Futagawa and Hinagu faults (e.g., Himematsu and Furuya 2016; Fujiwara et al. 2016; Fig S14b). While postseismic deformation was detected by
ALOS-2 InSAR (Fujiwara et al. 2016; Kobayashi 2018; Hashimoto 2020), the detailed temporal evolution was not revealed due to infrequent observations (2-4 times/year in general). This study shows the spatially and temporally detailed postseismic deformation revealed by the Sentinel-1 LiCSAR products and LiCSBAS, which is essential for understanding the complex postseismic deformation mechanism (Figs. 15 and S14).

Only the postseismic acquisitions (i.e., after April 16, 2016) of Sentinel-1 were used. The reference point was manually selected at the 950464 GNSS station, which is far from the deformed region (Fig. 15a, b). Two ascending data sets had long acquisition gaps between the summer of 2018 and 2019, which prevented the observation of detailed temporal behavior. However, the long interferograms spanning the gap had sufficient coherence, and therefore no gap in the SB network (i.e., no effect of temporal constraint in the SB inversion, see Morishita et al. 2020) was generated.

Subsequently, the LOS deformation time series was compared with the GNSS data at two GNSS stations (950465 and 021071; Fig. 15f). Each time series largely 

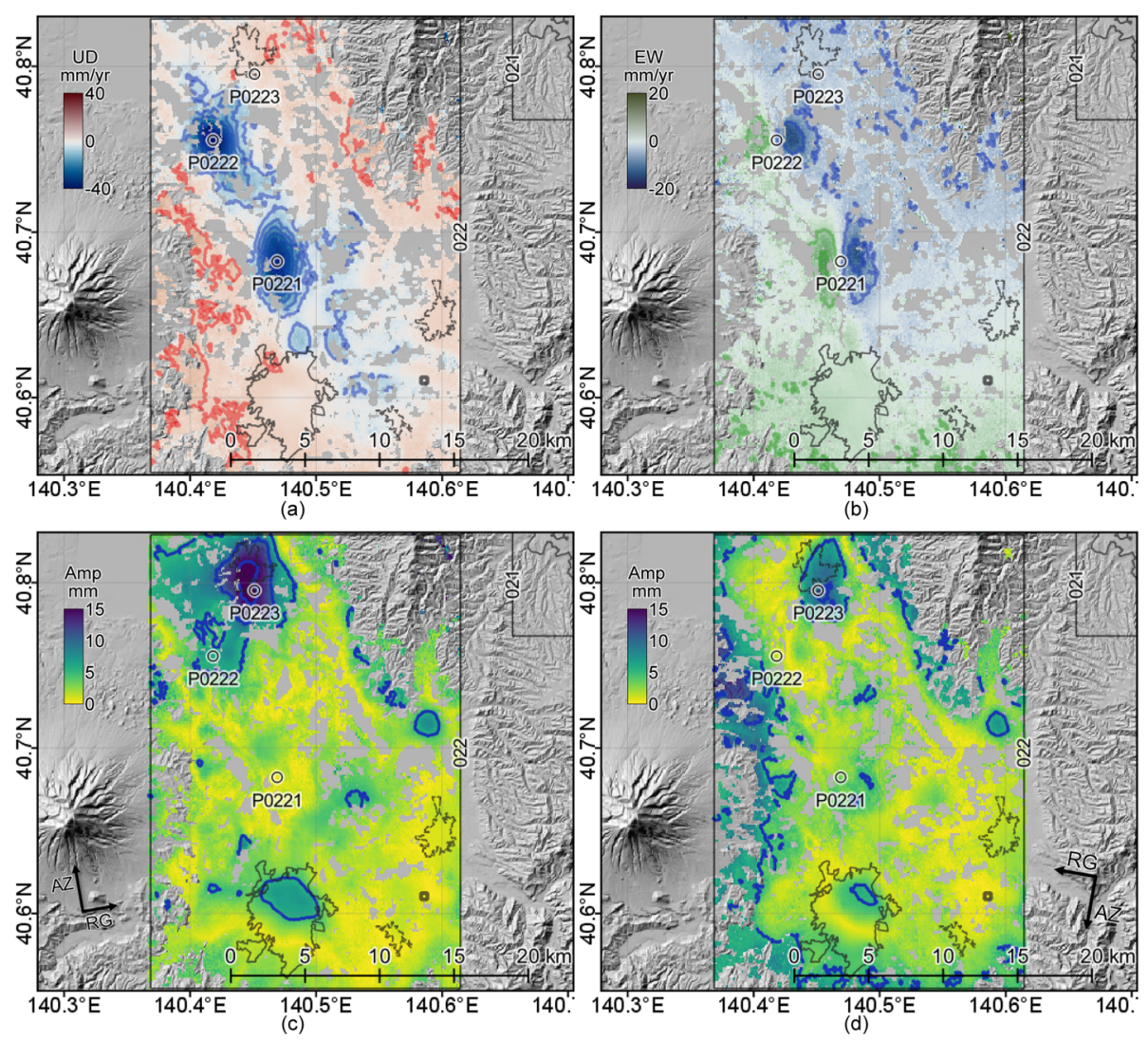

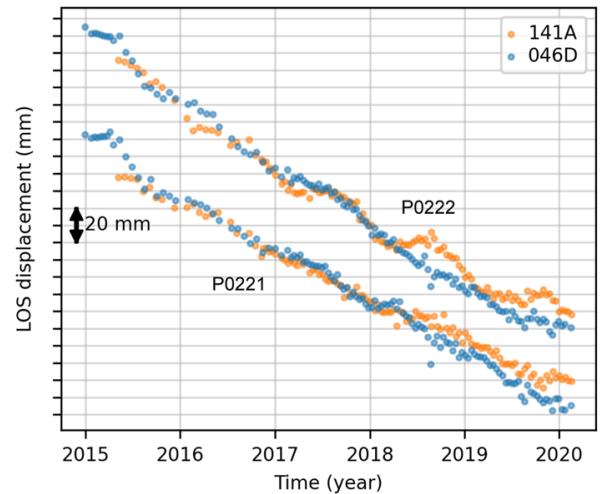

(e)

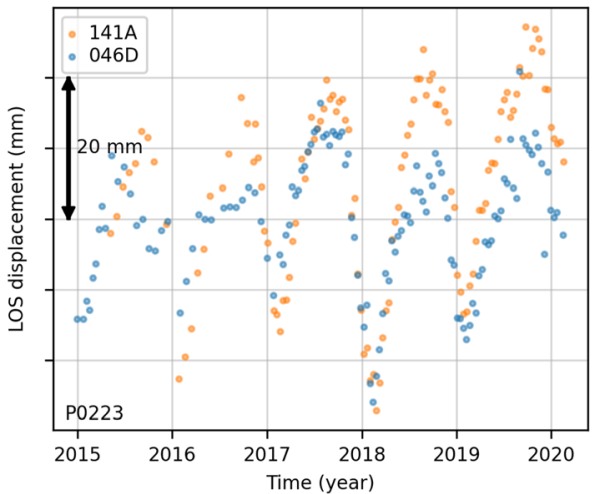

(f)

Fig. 10 a Unmasked vertical deformation velocities in Hirosaki (ID: 022). The black lines denote the outlines of the DID. The interval of the red (uplift) and blue (subsidence) contour lines is $5 \mathrm{~mm} /$ year without the $0 \mathrm{~mm} /$ year lines. The black square denotes the reference point. $\mathbf{b}$ Unmasked EW deformation velocities. The interval of the green (eastward) and blue (westward) contour lines is $5 \mathrm{~mm} /$ year without the $0 \mathrm{~mm} /$ year lines. c Amplitudes of the annual LOS fluctuation from the ascending 141A_04925_131313. The interval of the contour lines is $5 \mathrm{~mm}$. $\mathbf{d}$ Amplitudes from the descending 046D_04907_081313. e LOS deformation time series at P0221 and P0222 for each frame. f LOS deformation time series at P0223 for each frame

agreed with each other, and all standard deviations of the difference between InSAR and GNSS were less than $1 \mathrm{~cm}$, which is consistent with the uncertainty estimated in Morishita et al. (2020).

The EW component (Fig. 15b) showed that the entire region, except the west side of the Hinagu Fault, moved westward. This is opposite from the coseismic deformation caused by the right-lateral strike-slip and is considered to be attributed to viscoelastic relaxation of the lower crust and upper mantle (Pollitz et al. 2017; Kobayashi 2018).

The vertical component (Fig. 15a) showed more complex signals than the EW component. Around the west coast of the western extension of the Futagawa Fault (P4311), significant subsidence was detected. The temporal behavior showed exponential decay, which implies 


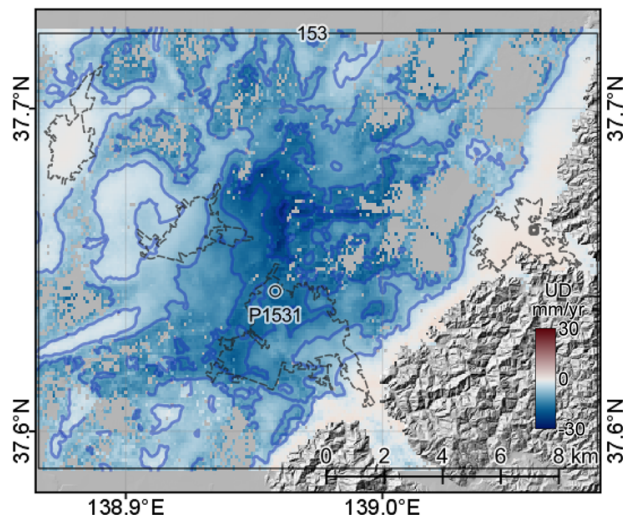

(a)

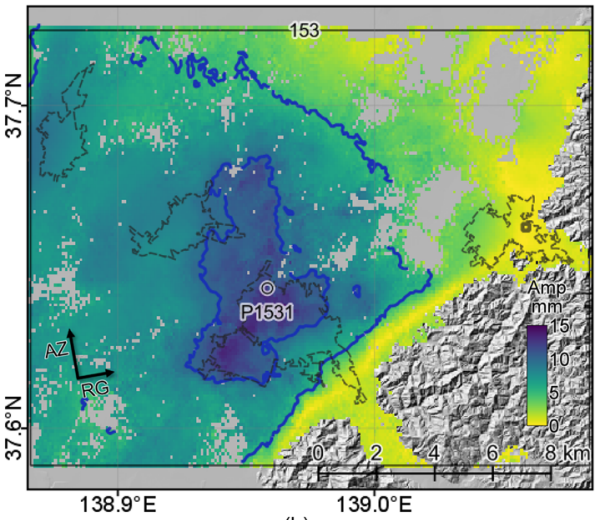

(b)

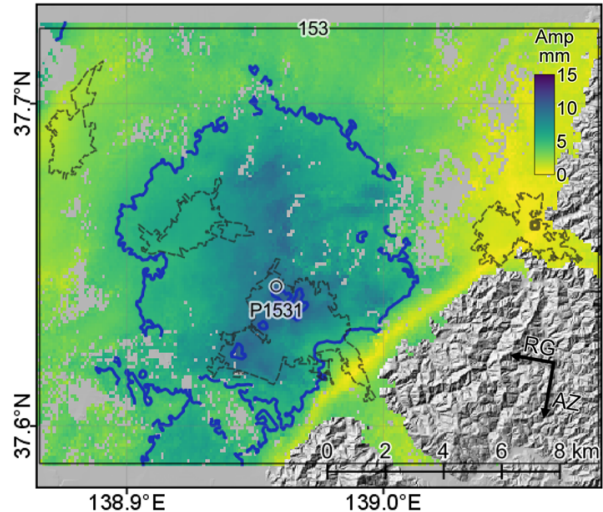

(c)

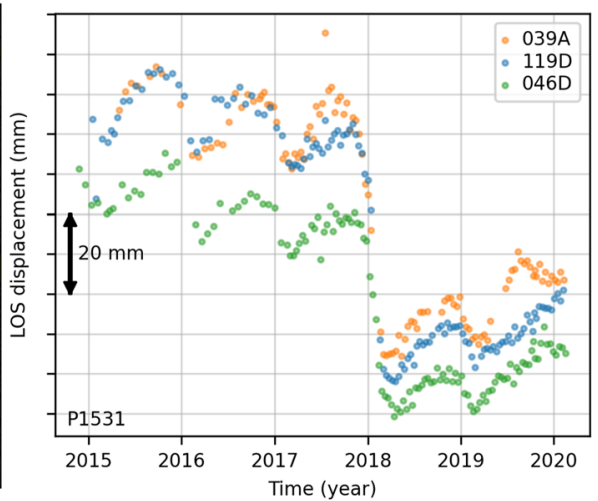

(d)

Fig. 11 a Vertical deformation velocities in Sanjo (ID: 153). The black lines denote the outlines of the DID. The interval of the blue (subsidence) contour lines is $5 \mathrm{~mm} / \mathrm{year}$ without the $0 \mathrm{~mm} /$ year lines. The black square denotes the reference point. $\mathbf{b}$ Amplitudes of the annual LOS fluctuation from the ascending 039A_05193_040711. The interval of the contour lines is $5 \mathrm{~mm}$. c Amplitudes from the descending 119D_05226_070704. $\mathbf{d}$ LOS deformation time series at P1531 for each frame

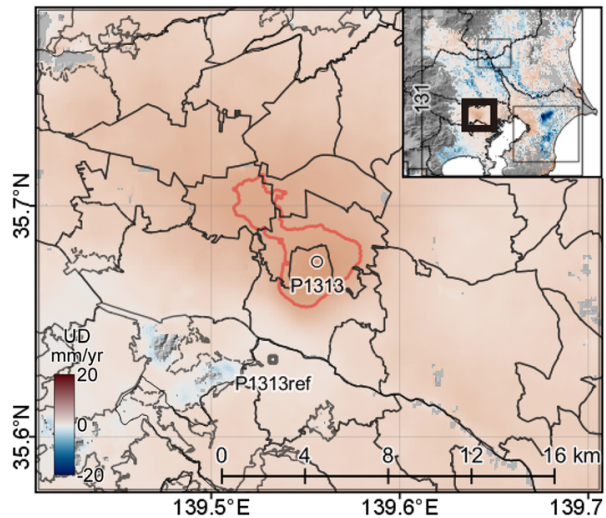

(a)

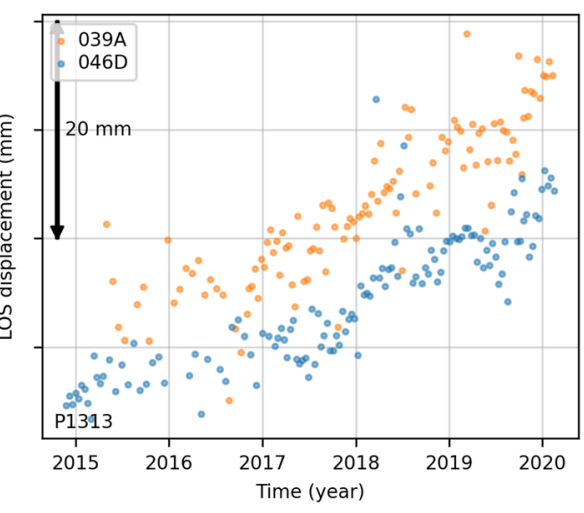

(b)

Fig. 12 a Vertical deformation velocities in Chofu (ID: 131, Tokyo in Kanto). The black lines denote the outlines of the DID. The interval of the red (uplift) contour lines is $5 \mathrm{~mm} /$ year without the $0 \mathrm{~mm} /$ year lines. The inset denotes the whole area of the 131 Kanto. $\mathbf{b}$ LOS deformation time series at P1313 with reference to P1313ref for each frame 


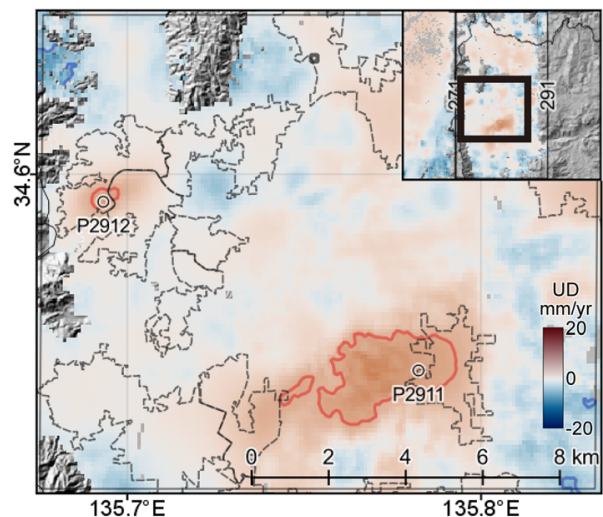

(a)

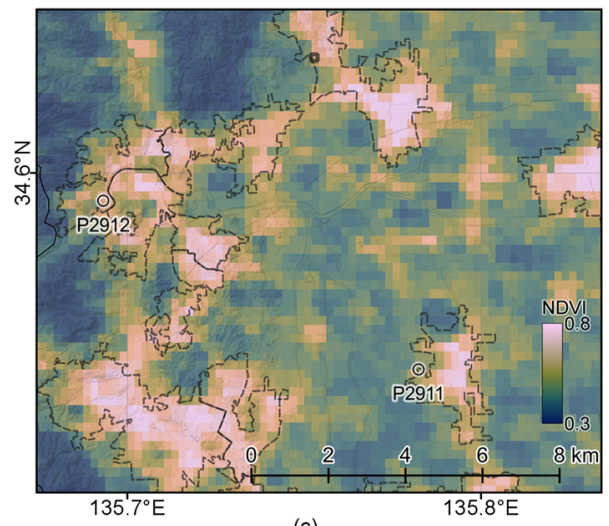

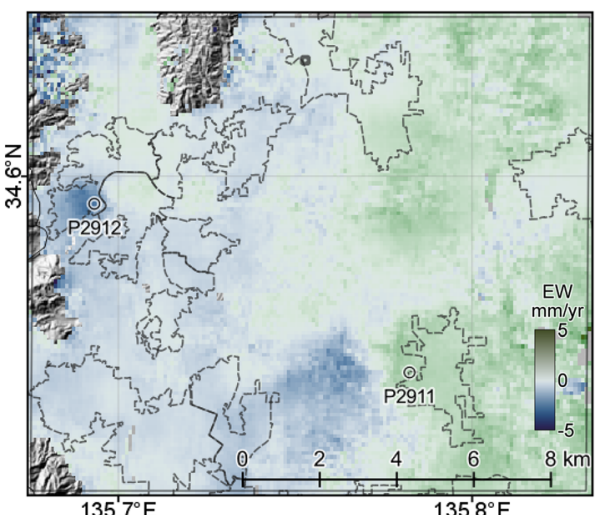

(b)

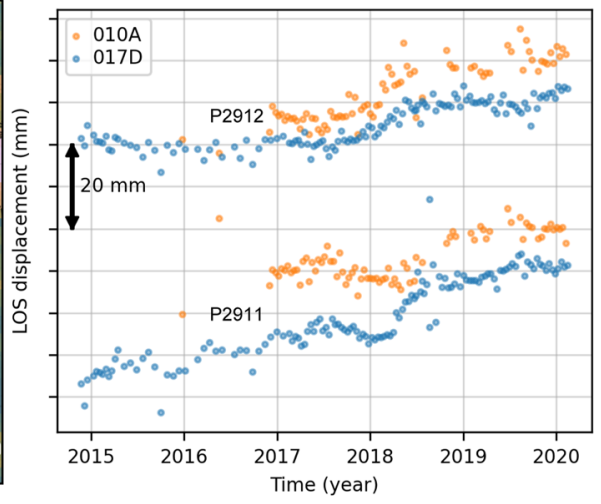

(d)

Fig. 13 a Vertical deformation velocities in a part of Nara prefecture (ID: 291). The black lines denote the outlines of the DID. The interval of the red (uplift) and blue (subsidence) contour lines is $5 \mathrm{~mm} /$ year without the $0 \mathrm{~mm} /$ year lines. The black square denotes the reference point. The inset denotes the whole area of the 291 Nara. b EW deformation velocities. c NDVI. (d) LOS deformation time series at P2912 and P2911 for each frame

that afterslip is the dominant source of this subsidence (Fig. 15c). Similar downward velocities were also observed by ALOS-2 (Kobayashi 2018; Hashimoto 2020). Because most of this region is covered with rice paddy fields (Figure S14a), this subsidence signal may include the bias related to fading signals (see the Section 4.1).

Around the Suizenji Park (P4312), exponentially decaying localized subsidence was detected (Fig. 15d). Dip-slip coseismic deformation occurred in this region and is considered to have been triggered by the motion of the main seismogenic Futagawa Fault and associated extensional strain field (Fujiwara et al. 2016, 2020). The time constant of the exponential decay seemed to be shorter than that of $\mathrm{P} 4311$, and the subsidence almost stopped around 2018. The consistent temporal behavior using only the Sentinel-1 descending data and infrequent ALOS-2 data was also reported in Bischoff et al. (2020) and Hashimoto (2020), respectively.

Large postseismic deformations were observed across the Hinagu Fault (Fig. 15e), while the coseismic deformation was much smaller than that of the Futagawa Fault
(Himematsu and Furuya 2016; He et al. 2019; Kobayashi et al. 2019). Because the ascending and descending LOS deformations showed opposite trends, the horizontal, rather than the vertical, component was dominant. The detected EW deformation is consistent with right-lateral slip along the Hinagu Fault. Considering the northnortheast strike direction, NS deformation would be much larger than EW deformation, though InSAR has almost no sensitivity to the NS component.

Almost no measurement points were obtained in the southeast side of the faults because the region is covered with dense vegetation. Although L-band ALOS-2 can retain sufficient coherence in these areas, the temporal sampling frequency is much lower and the detailed temporal evolution of the postseismic deformation cannot be revealed (Hashimoto 2020). The next-generation Lband SAR missions with high observation frequency such as ALOS-4 (Motohka et al. 2019) or NASA-ISRO SAR (NISAR; Jet Propulsion Laboratory 2020) will help clarify the complex postseismic deformation, even in such densely vegetated regions. 

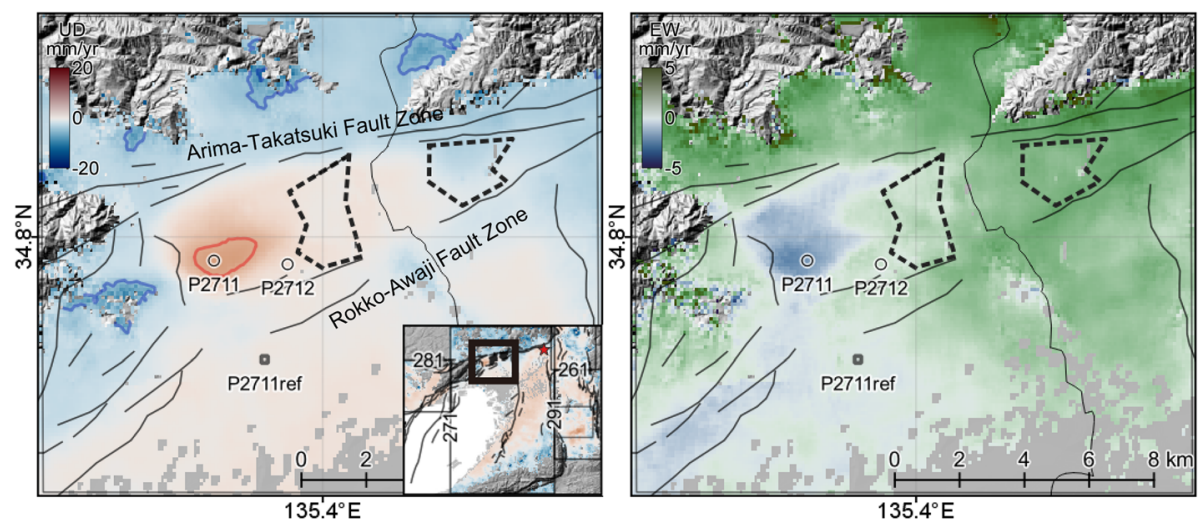

(a)
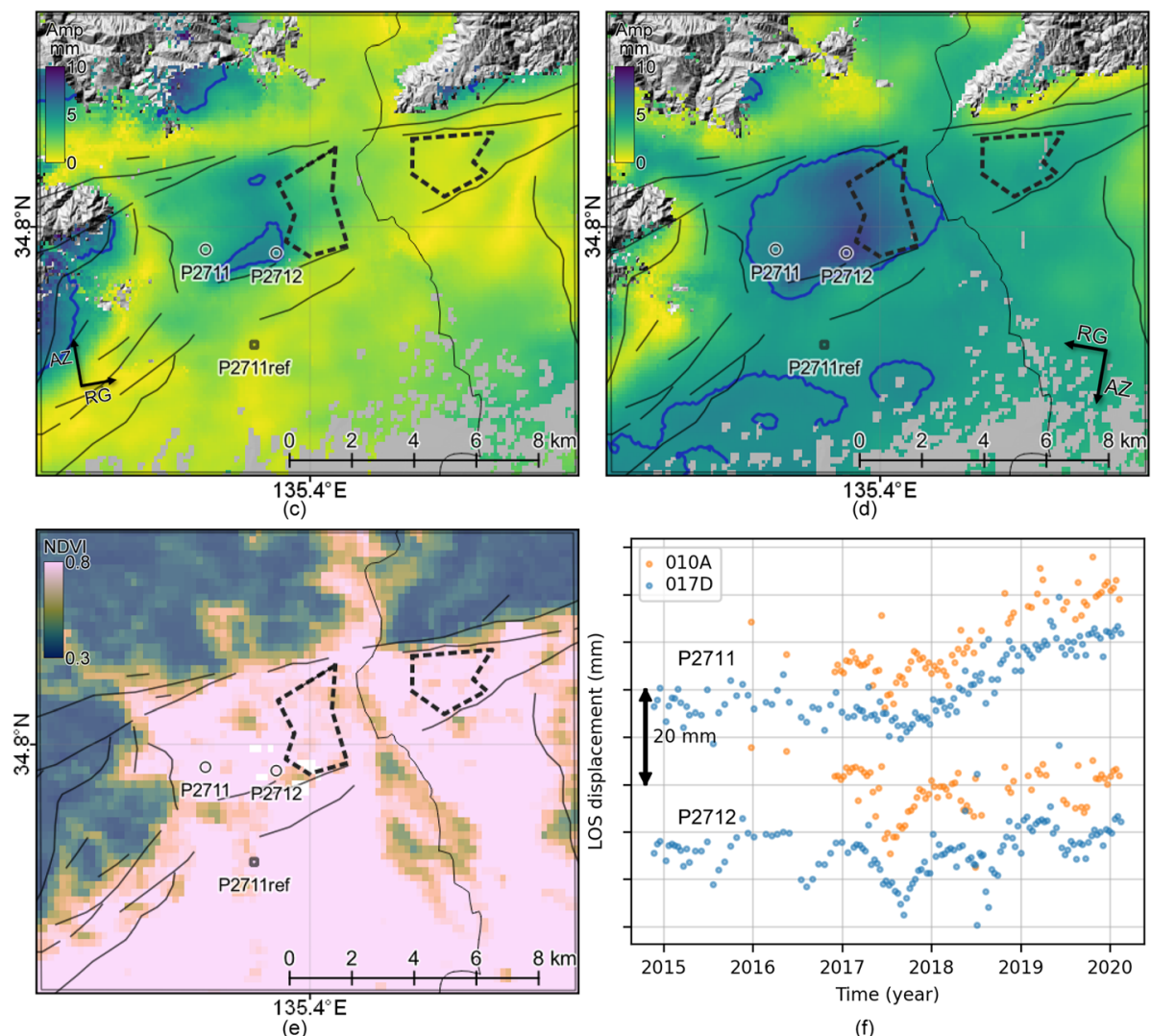

(f)

Fig. 14 a Vertical deformation velocities in a part of Osaka prefecture (ID: 271). The black solid lines denote the faults (The Headquarters for Earthquake Research Promotion 2020a, 2020b). The black bold dashed lines denote the outlines of the subsided areas until 2010 (Hashimoto 2016). The interval of the red (uplift) and blue (subsidence) contour lines is $5 \mathrm{~mm} /$ year without the $0 \mathrm{~mm} /$ year lines. The inset denotes the whole area of the 271 Osaka, and the red star denotes the epicenter of the Mw 5.6 earthquake on June 18, 2018. b EW deformation velocities. c Amplitudes of the annual LOS fluctuation from the ascending 010A_05549_121311. The interval of the contour lines is $5 \mathrm{~mm}$. d Amplitudes from the descending 017D_05514_131312. e NDVI. f LOS deformation time series at P2711 and P2712 with reference to P2711 ref for each frame

\section{Discussion}

\subsection{Possible bias due to the fading signal}

Ansari et al. (2020) reported that multilooked interferograms with short temporal baselines contain a fading signal, and the resulting time series and velocities are contaminated by a significant systematic bias when only the temporally short interferograms are used. The fading signal is considered to be created by soil moisture change or biomass growth (De Zan et al. 2014, 2015; De Zan and Gomba 2018; Ansari et al. 2020). Because LiCSAR products consist of temporally short interferometric pairs, the impact of the systematic bias could be significant.

In this study, several subsidence signals were observed outside of the DID, and the distribution of the subsidence signals was consistent with rice paddy fields (Figs. 16a, b and S5-S14), which almost all 


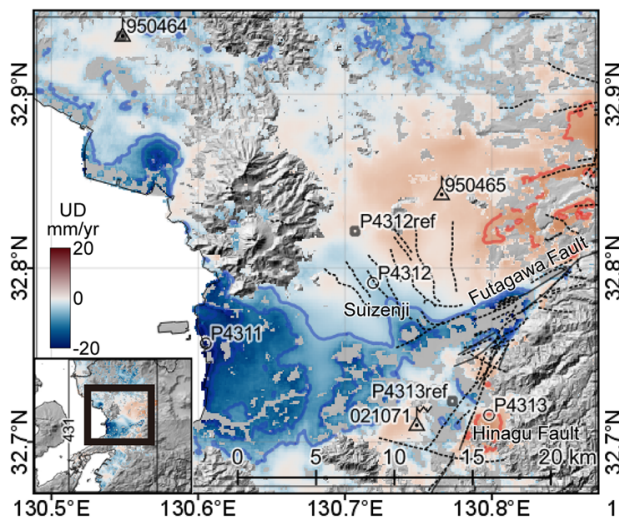

(a)

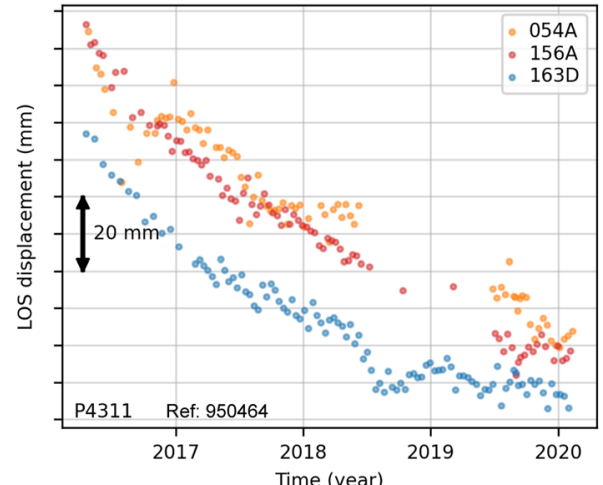

(c)

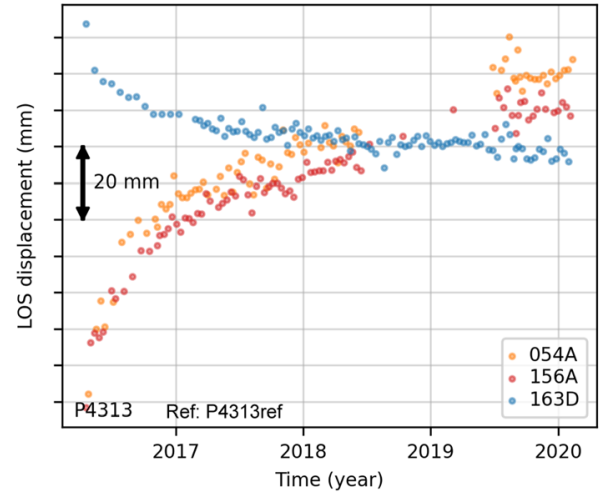

(e)

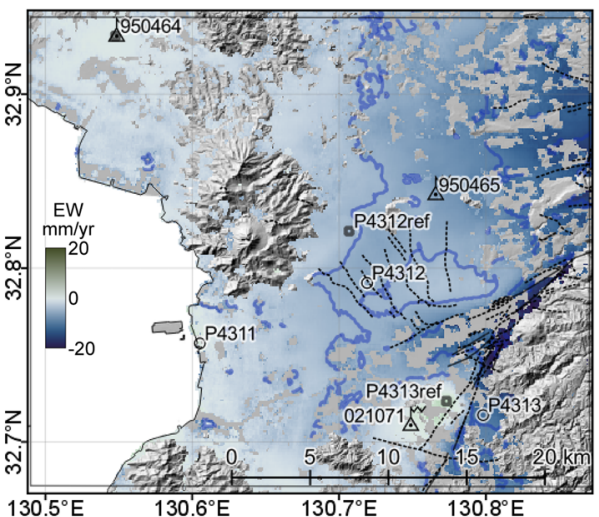

(b)

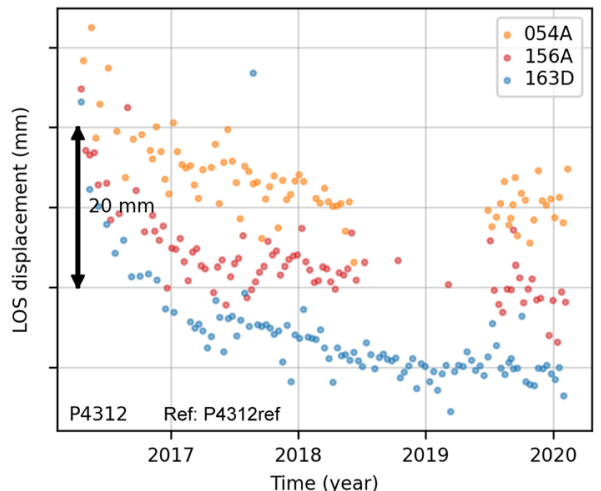

(d)

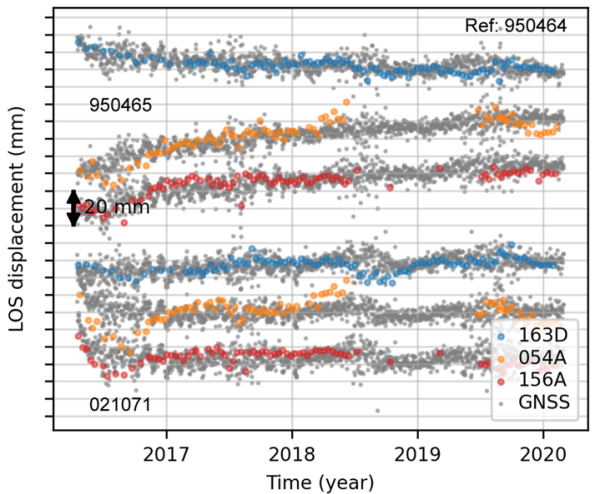

(f)

Fig. 15 a Vertical deformation velocities in a part of Kumamoto prefecture (ID: 431). The black dashed lines denote the small displacement lineaments identified by Fujiwara et al. (2016). The interval of the red (uplift) and blue (subsidence) contour lines is $5 \mathrm{~mm} / \mathrm{year}$ without $0 \mathrm{~mm} /$ year lines. The reference point is the 950464 GNSS station denoted by a triangle. The inset denotes the whole area of the 431 Kumamoto. $\mathbf{b}$ EW deformation velocities. c LOS deformation time series at P4311 (west coast) with reference to the 950464 GNSS station for each frame. d LOS deformation time series at P4312 (the Suizenji Park) with reference to P4312ref for each frame. e LOS deformation time series at P4313 (the Hinagu Fault) with reference to P4313ref for each frame. f LOS deformation time series at the 950465 and 021071 GNSS stations with reference to the 950464 for each frame and corresponding GNSS observations

show some degree of subsidence. Most of the rice paddy fields had no significant annual deformation component. It might be true that the amount of soil in rice paddy fields is slowly decreasing or underground layers are slowly compacting due to groundwater usage; however, it is also possible that common subsidence signals are created by the systematic bias from the fading signal. Soil moisture change and biomass growth in the rice paddy fields are more drastic than natural herbaceous fields. However, not all subsidence signals are attributed to systematic bias. In the urbanized DID, the impact of the fading signal is negligible, and the detected signals represent true ground deformation. 

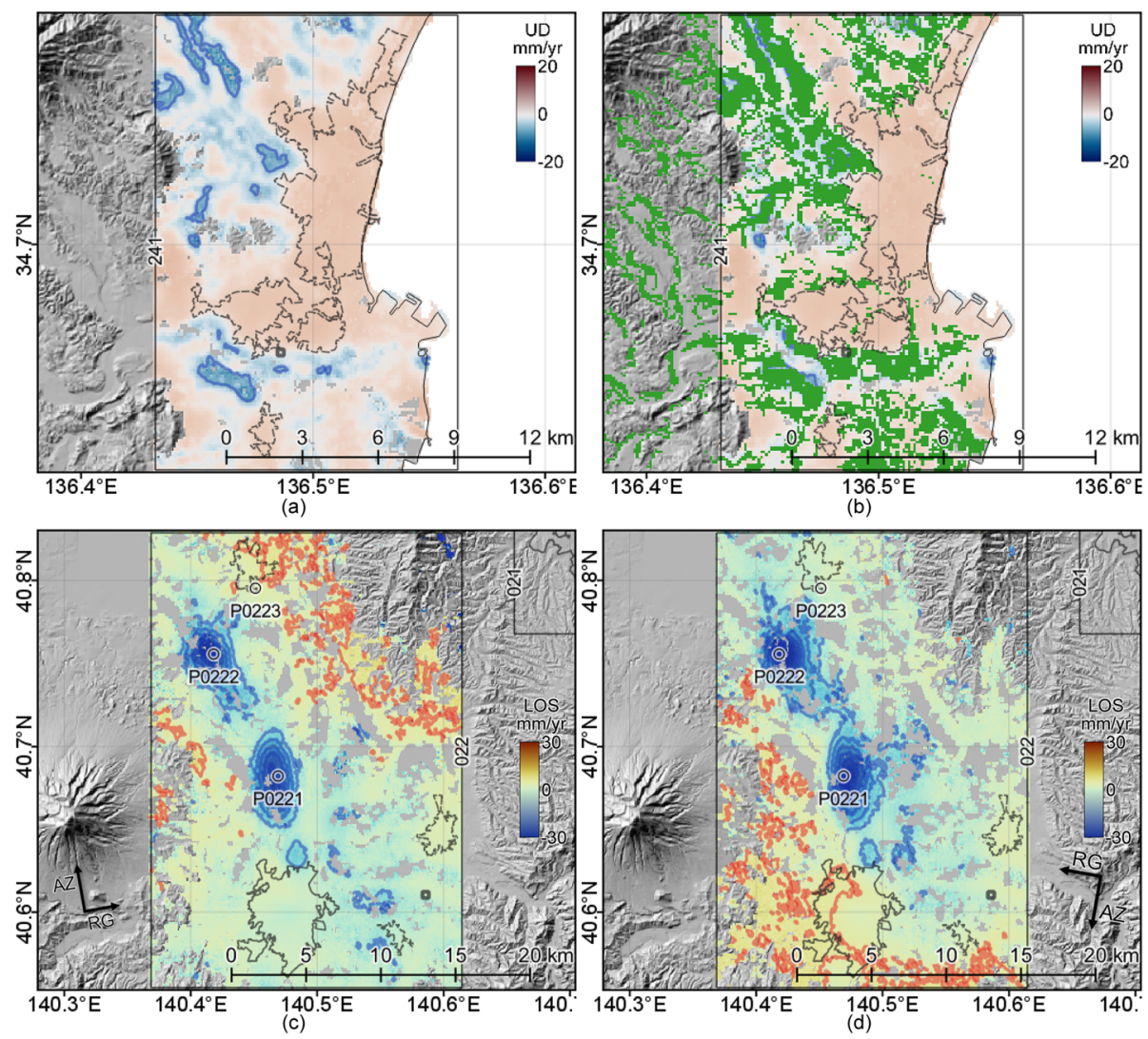

Fig. 16 a Vertical deformation velocities in Tsu (ID: 241). The black lines denote the outlines of the DID. The interval of the blue (subsidence) contour lines is $5 \mathrm{~mm} /$ year without the $0 \mathrm{~mm} /$ year lines. The black square denotes the reference point. $\mathbf{b}$ Shows the same information as (a) but overlaid with the green rice paddy fields. c Unmasked LOS deformation velocities from the ascending 141A_04925_131313 in Hirosaki (ID: 022). The interval of the red (LOS shortening) and blue (LOS extension) contour lines is $5 \mathrm{~mm} /$ year without the $0 \mathrm{~mm} /$ year lines. $\mathbf{d}$ Unmasked LOS deformation velocities from the descending 046D_04907_081313

Independent data sets observed from different geometries also help distinguish the true deformation signals from the systematic bias. Because the source of the systematic bias should be on the ground surface, multiple data sets would show the biased signal at the same locations. However, a deformation source related to groundwater or tectonic activity is underground and generates a horizontal component, which shifts the peak location and distorts the shape of the deforming region when viewed from an oblique LOS (Fuhrmann and Garthwaite 2019). Therefore, LOS deformations observed from ascending and descending orbits have different peak locations (Fig. 16c, d). Observations from multiple geometries are useful for both decomposition to the horizontal and vertical components and for distinguishing the true deformation with the source at depth from the surficial systematic bias.

\subsection{Applicability to other areas worldwide}

Because all the LiCSAR products and software used in this study are open and freely available, anyone can perform the same processing and obtain the same results. LiCSBAS automatically downloads the LiCSAR products, clips the area of interest, and performs the time series analysis with predefined parameters.

LiCSBAS processing after clipping in step $0-5$ can be done quickly if the area of interest is narrow, while the downloading time of the LiCSAR products in the step 0-1 highly depends on the user's internet speed (Morishita et al. 2020). For example, the Nara area (ID: 291) has a dimension with $36 \times 20 \mathrm{~km}(324 \times 216$ pixel), and 81 and 133 epochs in the ascending and descending orbits, respectively. A low-cost small single-board computer Raspberry Pi 4 (Quad core Cortex-A72 1.5 GHz, 4 GB Random Access Memory) was used for a processing test. The processing time was $\sim 10$ and $\sim 20 \mathrm{~min}$ for data conversion (step $0-2$ ) and $\sim 20$ and $\sim 35$ min for clipping (step 0-5) to the time series analysis (step 1), for the ascending and descending data, respectively. The file size was 3.6 and $6.3 \mathrm{~GB}$ for the downloaded LiCSAR products, 9.8 and $17 \mathrm{~GB}$ after data conversion, and 0.3 
and 0.4 GB after clipping, for the ascending and descending data, respectively. These facts indicate that users need not have high-performance computing resources or large amounts of storage, which are necessary for general InSAR processing from large low-level data (e.g., Single Look Complex).

Although this study focuses on Japan, this method is easily applicable to other areas wherever sufficient LiCSAR products are available. The LiCSAR system has produced its products mainly in high-priority areas (i.e., the Alpine-Himalayan Belt, East African Rift System, and > 1000 global volcanoes); 300,000 interferograms are available as of July 2020, and the coverage is being expanded (Lazecký et al. 2020). Even if the LiCSAR products have not been processed in the frame of interest, users can request processing from the LiCSAR frame request form on the COMET-LiCSAR web portal (COMET 2020).

The approach used in this study is also applicable to volcanoes, unless they are covered with dense vegetation. Unfortunately, most Japanese volcanoes are covered by forests, from which LiCSAR products derived from the C-band Sentinel-1 data cannot retain adequate coherence for the LiCSBAS time series analysis, even with short temporal baselines. To reveal deformation in such densely vegetated areas, L-band SAR data are preferred. It is difficult to detect the detailed deformation time series using existing L-band SAR data because the observation frequency for interferometry of the unique operating L-band satellite ALOS-2 is much lower $(<10$ times/year) than that of Sentinel-1 (30-60 times/year). However, nextgeneration L-band SAR satellites such as ALOS-4 (Motohka et al. 2019) and NISAR (Jet Propulsion Laboratory 2020), which have higher frequency observation capabilities comparable to Sentinel-1, will enable detailed deformation monitoring even in forested areas.

\subsection{Toward continuous operational monitoring}

The deformation time series and velocities should be updated with newly acquired data by reprocessing for continuous monitoring. The LiCSAR products in prioritized regions are continuously updated (Lazecký et al. 2020). In the current LiCSBAS processing chain, all steps in data preparation (step 0 ) process only new data (i.e., do not reprocess the existing data); thus, new data can be efficiently added. However, all steps in the time series analysis (step 1) must be reprocessed to update the results. If the area of interest is small, the reprocessing is relatively quick (see the Section 4.2). Nevertheless, reprocessing all the time series analysis steps with every new acquisition is not efficient, because the existing results are hardly changed. A more efficient approach to updating the results (e.g., processing only a small part related to new data) should be implemented. Additionally, the preferred update frequency depends on the needs of the end users. The update strategy should be determined considering the objective of the monitoring activity.

In this study, the deformation signals are identified by visual inspection of the velocities. Small, nonlinear deformation, especially that occurring near the edges of the observation period, might be missed. Introducing automatic change detection methods (e.g., Gaddes et al. 2019) could reduce missing true deformation signals and manual operations.

Some areas are masked due to unwrapping errors included in the LiCSAR products. If the number of the unwrapping errors is small, the errors can be corrected using the redundant network of the SB interferograms (Yunjun et al. 2019) and the masked deformation data may be usable. Although currently LiCSBAS does not support the unwrapping error correction, it would be worth experimenting and implementing.

\section{Conclusions}

This study performed an InSAR time series analysis using the LiCSAR products and LiCSBAS for 73 major urban areas in Japan and revealed the spatially and temporally detailed deformation time series and velocities during 2014-2020. All LiCSBAS processing was automatically performed using predefined parameters. Many deformation signals including linear/nonlinear subsidence/uplift and annual fluctuations were comprehensively detected with high accuracy. Additionally, the detailed postseismic response to the 2016 Kumamoto earthquake was detected using the approach developed in this study. All deformation data obtained in this study, including those not mentioned above, are available on an open repository (see "Availability of data and material") and are expected to be used for further research or interpretation. This nationwide monitoring approach using the LiCSAR products and LiCSBAS is easy to implement and applicable to other areas globally.

\section{Supplementary Information}

The online version contains supplementary material available at https://doi. org/10.1186/s40645-020-00402-7.

Additional file 1: Figure S1. Map of the clipped urban areas and topography of Japan. Figure S2. (a) Vertical deformation velocities overlaid with the green rice paddy fields in Tomakomai (ID: 016). The black lines denote the outlines of the DID. The interval of the blue (subsidence) contour lines is $5 \mathrm{~mm} / \mathrm{yr}$ without the $0 \mathrm{~mm} / \mathrm{yr}$ lines. The black square denotes the reference point. (b) EW deformation velocities. (c) Topography. (d) LOS deformation time series at P0161 for each frame. 
Figure S3. (a) Vertical deformation velocities overlaid with the green rice paddy fields in Kesennuma (ID: 042). The black lines denote the outlines of the DID. The interval of the blue (subsidence) contour lines is $5 \mathrm{~mm} / \mathrm{yr}$ without the $0 \mathrm{~mm} / \mathrm{yr}$ lines. The black square denotes the reference point. (b) EW deformation velocities. (c) Topography. (d) LOS deformation time series at P0421 for each frame. Figure S4. Kanto (ID: 131). The black lines denote the outlines of the DID. The interval of the red (uplift) and blue (subsidence) contour lines is $5 \mathrm{~mm} / \mathrm{yr}$ without the $0 \mathrm{~mm} / \mathrm{yr}$ lines. The black square around center denotes the reference point. (a) Vertical deformation velocities overlaid with the green rice paddy fields. (b) EW deformation velocities. (c) Topography. (d) LOS deformation velocities from the 039A 05372 151515. (e) LOS deformation velocities from the 141A_05337_160700. (f) LOS deformation velocities from the 046D_05469_071311 and 046D_05292_131313. Figure S5. (a) Vertical deformation velocities overlaid with the green rice paddy fields in Niigata (ID: 151). The black lines denote the outlines of the DID. The interval of the blue (subsidence) contour lines is $5 \mathrm{~mm} / \mathrm{yr}$ without the $0 \mathrm{~mm} / \mathrm{yr}$ lines. The black square denotes the reference point. (b) EW deformation velocities. (c) Topography. ( $d-f)$ LOS deformation velocities from the 039A_05193_040711,046D_05292_131313, and 119D_05226_070704, respectively. Figure S6. (a) Vertical deformation velocities overlaid with the green rice paddy fields in Kanazawa (ID: 171). The black lines denote the outlines of the DID. The interval of the red (uplift) and blue (subsidence) contour lines is $5 \mathrm{~mm} / \mathrm{yr}$ without the $0 \mathrm{~mm} / \mathrm{yr}$ lines. The black square denotes the reference point. (b) EW deformation velocities. (c) Topography. (d-f) LOS deformation velocities from the 112A_05300_030808,017D_05353_130400, and 119D_05372_141313, respectively. Figure S7. (a) Vertical deformation velocities overlaid with the green rice paddy fields in Yamagata (ID: 061). The black lines denote the outlines of the DID. The interval of the blue (subsidence) contour lines is $5 \mathrm{~mm} / \mathrm{yr}$ without the $0 \mathrm{~mm} / \mathrm{yr}$ lines. The black square denotes the reference point. (b) EW deformation velocities. (c) Topography. (d,e) LOS deformation velocities from the 141A_05118_131311 and

046D_05096_121313, respectively. Figure S8. (a) Vertical deformation velocities overlaid with the green rice paddy fields in Yonezawa (ID: 062). The black lines denote the outlines of the DID. The black square denotes the reference point. (b) EW deformation velocities. (c) Topography. (d-f) LOS deformation velocities from the 039A_05193_040711,

141A_05118_131311, and 046D_05292_131313, respectively. Figure S9. (a) Vertical deformation velocities overlaid with the green rice paddy fields in Ojiya (ID: 155). The black lines denote the outlines of the DID. The interval of the red (uplift) and blue (subsidence) contour lines is 5 $\mathrm{mm} / \mathrm{yr}$ without the $0 \mathrm{~mm} / \mathrm{yr}$ lines. The black square denotes the reference point. (b) EW deformation velocities. (c) Topography. (d-f) LOS deformation velocities from the 039A_05372_151515,

046D_05292_131313, and 119D_05226_070704, respectively. Figure S10. (a) Masked vertical deformation velocities in Hirosaki (ID: 022). The black lines denote the outlines of the DID. The interval of the red (uplift) and blue (subsidence) contour lines is $5 \mathrm{~mm} / \mathrm{yr}$ without the $0 \mathrm{~mm} / \mathrm{yr}$ lines. The black square denotes the reference point. (b) Unmasked vertical deformation velocities overlaid with the green rice paddy fields. (c) Topography. Figure S11. (a) Vertical deformation velocities overlaid with the green rice paddy fields in Sanjo (ID: 153). The black lines denote the outlines of the DID. The interval of the blue (subsidence) contour lines is $5 \mathrm{~mm} / \mathrm{yr}$ without the $0 \mathrm{~mm} / \mathrm{yr}$ lines. The black square denotes the reference point. (b) EW deformation velocities. (c) Topography. (d-f) LOS deformation velocities from the 039A_05193_040711,

046D_05292_131313, and 119D_05226_070704, respectively. Figure S12. (a) Vertical deformation velocities overlaid with the green rice paddy fields in Nara (ID: 291). The black lines denote the outlines of the DID. The interval of the red (uplift) and blue (subsidence) contour lines is 5 $\mathrm{mm} / \mathrm{yr}$ without the $0 \mathrm{~mm} / \mathrm{yr}$ lines. The black square denotes the reference point. (b) Topography. (c,d) LOS deformation velocities from the 010A_05549_121311 and 017D_05514_131312, respectively. Figure S13. (a) Vertical deformation velocities overlaid with the green rice paddy fields in Osaka (ID: 271). The black lines denote the outlines of the DID. The interval of the red (uplift) and blue (subsidence) contour lines is $5 \mathrm{~mm} / \mathrm{yr}$ without the $0 \mathrm{~mm} / \mathrm{yr}$ lines. The black square denotes the reference point. (b) Topography. (c,d) LOS deformation velocities from the 010A_05549_121311 and 017D_05514_131312, respectively. Figure
S14. (a) Vertical deformation velocities overlaid with the green rice paddy fields in Kumamoto (ID: 431). The black lines denote the outlines of the DID. The interval of the red (uplift) and blue (subsidence) contour lines is $5 \mathrm{~mm} / \mathrm{yr}$ without the $0 \mathrm{~mm} / \mathrm{yr}$ lines. The black square denotes the reference point. (b) A coseismic ALOS-2 SAR interferogram between March 7 and April 18, 2016, available on GSIMaps (https://maps.gsi.go.jp/). (c) Topography. (d-f) LOS deformation velocities from the

054A_05688_051313, 156A_05639_121313, and 163D_05736_131313, respectively. Table S1. LiCSBAS parameter settings used in this study. The name of the parameters are explained in the LiCSBAS script (https:// github.com/yumorishita/LiCSBAS)

\section{Abbreviations}

ALOS: Advanced Land Observing Satellite; COMET: Centre for the Observation and Modelling of Earthquakes, Volcanoes and Tectonics; DID: Densely inhabited district; ESA: European Space Agency; EW: East-west; GACOS: Generic Atmospheric Correction Online Service; GIS: Geographic information system; GNSS: Global Navigation Satellite System; GSI: Geospatial Information Authority of Japan; InSAR: Synthetic Aperture Radar Interferometry; JERS-1: Japanese Earth Resources Satellite-1; JAXA: Japan Aerospace Exploration Agency; LiCS: Looking Inside the Continents from Space; LiCSAR: Looking into Continents from Space with Synthetic Aperture Radar; LOS: Line-of-sight; NDVI: Normalized Difference Vegetation Index; NISA R: NASA-ISRO SAR; NS: North-south; RMS: Root mean square; SAR: Synthetic Aperture Radar; SB: Small baseline

\section{Acknowledgements}

LiCSAR contains modified Copernicus Sentinel data 2014-2020 analyzed by the COMET. LiCSAR uses JASMIN, the UK's collaborative data analysis environment (http://jasmin.ac.uk). The background images used in all figures are from GSI Tiles (https://maps.gsi.go.jp/development/ichiran.html).

\section{Author's contributions}

The author(s) read and approved the final manuscript.

\section{Funding}

YM was funded by the Japan Society for the Promotion of Science Overseas Research Fellowship and the Geospatial Information Authority of Japan.

\section{Availability of data and materials}

All the figures (LOS velocities, amplitude and time offset of the annual deformation, decomposed vertical and EW velocities, rice paddy fields, NDVI, optical images, topography, and SB network for all 191 data sets) and data generated in this study are available on the ZENODO repository, https://doi. org/10.5281/zenodo.4243151. The LiCSAR products are available on the COMET-LiCSAR-portal web (https://comet.nerc.ac.uk/COMET-LiCS-portal/). LiCSBAS is available on the GitHub, https://github.com/yumorishita/LiCSBAS. The GNSS data are available on the Geospatial Information Authority of Japan (GSI) website (https://terras.gsi.go.jp/). The NDVI data are derived from Terra/MODIS in August 2012, processed by GSI, and are available on the GSI website (https://www.gsi.go.jp/kankyochiri/ndvi-Modis_download.html). The GIS data of the DID and rice paddy fields are available on the Ministry of Land, Infrastructure, Transport and Tourism website (https://nlftp.mlit.go.jp/ ksj/index.html).

\section{Competing interests}

The author declares that they have no competing interest.

Received: 15 September 2020 Accepted: 21 December 2020 Published online: 12 January 2021

\section{References}

Ansari H, De Zan F, Parizzi A (2020) Study of systematic bias in measuring surface deformation with SAR Interferometry. IEEE Trans Geosci Remote Sens:1-1. https://doi.org/10.1109/TGRS.2020.3003421

Bell JW, Amelung F, Ferretti A et al (2008) Permanent scatterer InSAR reveals seasonal and long-term aquifer-system response to groundwater pumping and artificial recharge. Water Resour Res 44. https://doi.org/10.1029/ 2007WR006152 
Bischoff CA, Ferretti A, Novali F et al (2020) Nationwide deformation monitoring with SqueeSAR using Sentinel-1 data. Proc Int Assoc Hydrol Sci 382:31-37. https://doi.org/10.5194/piahs-382-31-2020

Blackwell E, Shirzaei M, Ojha C, Werth S (2020) Tracking California's sinking coast from space: implications for relative sea-level rise. Sci Adv 6:eaba4551. https://doi.org/10.1126/sciadv.aba4551

Chaussard E, Amelung F, Abidin H, Hong SH (2013) Sinking cities in Indonesia: ALOS PALSAR detects rapid subsidence due to groundwater and gas extraction. Remote Sens Environ 128:150-161. https://doi.org/10.1016/j.rse. 2012.10.015

Chaussard E, Wdowinski S, Cabral-Cano E, Amelung F (2014) Land subsidence in central Mexico detected by ALOS InSAR time-series. Remote Sens Environ 140:94-106. https://doi.org/10.1016/j.rse.2013.08.038

COMET (2020) COMET-LiCS Sentinel-1 InSAR portal. https://comet.nerc.ac.uk/ COMET-LiCS-portal/. Accessed 24 June 2020

Crosetto M, Solari L, Mróz M et al (2020) The evolution of wide-area DInSAR: From regional and national services to the European Ground Motion Service. Remote Sens 12:2043. https://doi.org/10.3390/rs12122043

De Zan F, Gomba G (2018) Vegetation and soil moisture inversion from SAR closure phases: First experiments and results. Remote Sens Environ 217:562572. https://doi.org/10.1016/J.RSE.2018.08.034

De Zan F, Parizzi A, Prats-Iraola P et al (2014) A SAR interferometric model for soil moisture. IEEE Trans Geosci Remote Sens 52:418-425. https://doi.org/10.1109/ TGRS.2013.2241069

De Zan F, Zonno M, Lopez-Dekker P (2015) Phase inconsistencies and multiple scattering in SAR Interferometry. IEEE Trans Geosci Remote Sens 53:66086616. https://doi.org/10.1109/TGRS.2015.2444431

Fuhrmann T, Garthwaite MC (2019) Resolving three-dimensional surface motion with InSAR: Constraints from multi-geometry data fusion. Remote Sens 11: 241. https://doi.org/10.3390/rs11030241

Fujiwara S, Nakano T, Morishita Y (2020) Detection of triggered shallow slips caused by large earthquakes using L-band SAR interferometry. Earth Planets Space 72:119. https://doi.org/10.1186/s40623-020-01239-6

Fujiwara S, Yarai H, Kobayashi T et al (2016) Small-displacement linear surface ruptures of the 2016 Kumamoto earthquake sequence detected by ALOS-2 SAR interferometry. Earth Planets Space 68:160. https://doi.org/10.1186/ s40623-016-0534-X

Gaddes ME, Hooper A, Bagnardi M (2019) Using machine learning to automatically detect volcanic unrest in a time series of interferograms. J Geophys Res Solid Earth 124:12304-12322. https://doi.org/10.1029/ 2019JB017519

Hashimoto M (2016) Ground deformation in the Kyoto and Osaka area during recent 19 years detected with InSAR. In: International Association of Geodesy Symposia. Cham: Springer Verlag, pp 155-164. https://doi.org/10.1007/1345_ 2016_222

Hashimoto M (2020) Postseismic deformation following the 2016 Kumamoto Earthquake detected by ALOS-2/PALSAR-2. Earth Planets Space 72:154. https://doi.org/10.1186/s40623-020-01285-0

He P, Wen Y, Xu C, Chen Y (2019) Complete three-dimensional near-field surface displacements from imaging geodesy techniques applied to the 2016 Kumamoto earthquake. Remote Sens Environ 232:111321. https://doi.org/10. 1016/j.rse.2019.111321

Himematsu Y, Furuya M (2016) Fault source model for the 2016 Kumamoto earthquake sequence based on ALOS-2/PALSAR-2 pixel-offset data: evidence for dynamic slip partitioning. Earth Planets Space 68:169. https://doi.org/10. 1186/s40623-016-0545-7

Japan Meteorological Agency (2020) Search earthquake intensity database. https://www.data.jma.go.jp/svd/eqdb/data/shindo/index.php (in Japanese). Accessed 27 July 2020

Jet Propulsion Laboratory (2020) NASA-ISRO SAR Mission (NISAR). https://nisar.jpl. nasa.gov/. Accessed 27 July 2020

Kobayashi T (2018) Postseismic deformation of the 2016 Kumamoto Earthquake. In: Rep. Coord. Comm. Earthq. Predict https://cais.gsi.go.jp/YOCHIREN/report/ kaihou100/12_07.pdf (in Japanese). Accessed 3 Aug 2020

Kobayashi T, Yarai H, Kawamoto S et al (2019) Crustal deformation and fault models of the 2016 Kumamoto Earthquake sequence: foreshocks and main shock. In: International Association of Geodesy Symposia

Lazecký M, Spaans K, González PJ et al (2020) LiCSAR: an automatic InSAR tool for measuring and monitoring tectonic and volcanic activity. Remote Sens 12 : 2430. https://doi.org/10.3390/rs12152430
Manunta M, De Luca C, Zinno I et al (2019) The parallel SBAS approach for Sentinel-1 interferometric wide swath deformation time-series generation: algorithm description and products quality assessment. IEEE Trans Geosci Remote Sens 57. https://doi.org/10.1109/TGRS.2019.2904912

Ministry of Land, Infrastructure, Transport and Tourism (2015) Digital National Land Information (Densely Inhabited District). https://nlftp.mlit.go.jp/ksj/gml/ datalist/KsjTmplt-A16-v2_3.html (in Japanese). Accessed 24 June 2020

Ministry of the Environment (2019) The national ground environmental information directory - Ishikawa Prefecture, Kanazawa Plain. http://www.env. go.jp/water/jiban/directory/17ishikawa/kanazawa/index.html (in Japanese). Accessed 27 July 2020

Ministry of the Environment (2020) Overview of subsidence areas in Japan. https://www.env.go.jp/water/jiban/gaikyo/gaikyo30.pdf (in Japanese). Accessed 3 Aug 2020

Morishita Y, Lazecky M, Wright TJ et al (2020) LiCSBAS: an open-source InSAR time series analysis package integrated with the LiCSAR Automated Sentinel1 InSAR Processor. Remote Sens 12:424. https://doi.org/10.3390/rs12030424

Morishita Y, Suzuki A, Amagai T et al (2010) Approach to efficient leveling by using InSAR (in Japanese). J Geospatial Inf Auth Japan 120:17-22

Motagh M, Shamshiri R, Haghshenas Haghighi M et al (2017) Quantifying groundwater exploitation induced subsidence in the Rafsanjan plain, southeastern Iran, using InSAR time-series and in situ measurements. Eng Geol 218:134-151. https://doi.org/10.1016/j.enggeo.2017.01.011

Motohka T, Kankaku Y, Miura S, Suzuki S (2019) ALOS-4 L-Band SAR Mission and Observation. In: International Geoscience and Remote Sensing Symposium (IGARSS). Yokohama: Institute of Electrical and Electronics Engineers Inc., pp 5271-5273. https://doi.org/10.1109/IGARSS.2019. 8898169

Nakagawa H, Murakami M, Fujiwara S, Tobita M (2000) Land subsidence of the northern Kanto plains caused by ground water extraction detected by JERS-1 SAR interferometry. In: International Geoscience and Remote Sensing Symposium (IGARSS). Honolulu: IEEE, pp 2233-2235. https://doi.org/10.1109/ IGARSS.2000.858366

Nonaka T, Asaka T, Iwashita K, Ogushi F (2020) Evaluation of the trend of deformation around the Kanto Region estimated using the time series of PALSAR-2 Data. Sensors 20:339. https://doi.org/10.3390/s20020339

Pollitz FF, Kobayashi T, Yarai H et al (2017) Viscoelastic lower crust and mantle relaxation following the 14-16 April 2016 Kumamoto, Japan, earthquake sequence. Geophys Res Lett 44:8795-8803. https://doi.org/10.1002/ 2017GL074783

Potin P, Rosich B, Miranda N et al (2019) Copernicus Sentinel-1 Constellation Mission Operations Status. In: IGARSS 2019 - 2019 IEEE Int Geosci Remote Sens Symposium. IEEE, Yokohama, Japan, pp 5385-5388

Rosen PA, Hensley S, Zebker HA et al (1996) Surface deformation and coherence measurements of Kilauea Volcano, Hawaii, from SIR-C radar interferometry. J Geophys Res Planets 101:23109-23125. https://doi.org/ 10.1029/96JE01459

Samieie-Esfahany S, Hanssen RF, Van Thienen-Visser K, Muntendam-Bos A (2009) On the effect of horizontal deformation on InSAR subsidence estimates. In: Fringe 2009 Workshop

Sato HP, Abe K, Ootaki O (2003) GPS-measured land subsidence in Ojiya City, Niigata Prefecture, Japan. Eng Geol 67:379-390. https://doi.org/10.1016/ S0013-7952(02)00221-1

Shen SL, Tohno I, Nishgaki M, Miura N (2004) Land subsidence due to withdrawal of deep-groundwater. Lowl Technol Int 6:1-8

Suito H (2018) Current status of postseismic deformation following the 2011 Tohoku-Oki Earthquake. J Disaster Res 13:503-510. https://doi.org/10.20965/ jdr.2018.p0503

The Headquarters for Earthquake Research Promotion (2020a) Rokko-Awaji fault zone. https://www.jishin.go.jp/regional_seismicity/rs_katsudanso/f079_rokko_ awaji/ (in Japanese). Accessed 27 July 2020

The Headquarters for Earthquake Research Promotion (2020b) Arima-Takatsuki fault zone. https://www.jishin.go.jp/regional_seismicity/rs_katsudanso/f076_ arima takatsuki/ (in Japanese). Accessed 27 July 2020

Tochigi Prefecture (2011) Report on surveys of ground deformation and groundwater level in Tochigi in 2009. http://www.pref.tochigi.lg.jp/d03/eco/ kankyou/hozen/documents/21jiban.pdf (in Japanese). Accessed 27 July 2020

Tokyo Metropolitan Government (2019) Report of subsidence survey. https:// www.kensetsu.metro.tokyo.lg.jp/content/000045622.pdf (in Japanese). Accessed 14 July 2020 
Weiss JR, Walters RJ, Morishita Y et al (2020) High-resolution surface velocities and strain for Anatolia from Sentinel-1 InSAR and GNSS data. Geophys Res Lett. https://doi.org/10.1029/2020GL087376

Wright TJ, Parsons BE, Lu Z (2004) Toward mapping surface deformation in three dimensions using InSAR. Geophys Res Lett 31:L01607. https://doi.org/10. 1029/2003GL018827

Yamamoto S (1995) Recent trend of land subsidence in Japan. In: IAHS Publications-Series of Proceedings and Reports-Intern Assoc Hydrological Sciences. The Hague: IAHS Publ, p 487

Yu C, Li Z, Penna NT, Crippa P (2018) Generic Atmospheric Correction Model for Interferometric Synthetic Aperture Radar Observations. J Geophys Res Solid Earth 123:9202-9222. https://doi.org/10.1029/2017JB015305

Yunjun Z, Fattahi H, Amelung F (2019) Small baseline InSAR time series analysis: Unwrapping error correction and noise reduction. Comput Geosci 133: 104331. https://doi.org/10.1016/J.CAGEO.2019.104331

\section{Publisher's Note}

Springer Nature remains neutral with regard to jurisdictional claims in published maps and institutional affiliations.

\section{Submit your manuscript to a SpringerOpen ${ }^{\odot}$ journal and benefit from:}

- Convenient online submission

- Rigorous peer review

- Open access: articles freely available online

- High visibility within the field

- Retaining the copyright to your article

Submit your next manuscript at $\boldsymbol{\nabla}$ springeropen.com 